\title{
Blocking airway mucous cell metaplasia by inhibiting EGFR antiapoptosis and IL-13 transdifferentiation signals
}

\author{
Jeffrey W. Tyner, ${ }^{1}$ Edy Y. Kim, ${ }^{1}$ Kyotaro Ide, ${ }^{1}$ Mark R. Pelletier, ${ }^{1}$ William T. Roswit, ${ }^{1}$
} Jeffrey D. Morton, ${ }^{1}$ John T. Battaile, ${ }^{1}$ Anand C. Patel, ${ }^{2}$ G. Alexander Patterson, ${ }^{3}$ Mario Castro, ${ }^{1}$ Melanie S. Spoor, ${ }^{1}$ Yingjian You, ${ }^{1}$ Steven L. Brody, ${ }^{1}$ and Michael J. Holtzman ${ }^{1,4}$

${ }^{1}$ Pulmonary and Critical Care Medicine, Department of Medicine, ${ }^{2}$ Department of Pediatrics, ${ }^{3}$ Department of Surgery, and ${ }^{4}$ Department of Cell Biology, Washington University School of Medicine, St. Louis, Missouri, USA.

\begin{abstract}
Epithelial hyperplasia and metaplasia are common features of inflammatory and neoplastic disease, but the basis for the altered epithelial phenotype is often uncertain. Here we show that long-term ciliated cell hyperplasia coincides with mucous (goblet) cell metaplasia after respiratory viral clearance in mouse airways. This chronic switch in epithelial behavior exhibits genetic susceptibility and depends on persistent activation of EGFR signaling to PI3K that prevents apoptosis of ciliated cells and on IL-13 signaling that promotes transdifferentiation of ciliated to goblet cells. Thus, EGFR blockade (using an irreversible EGFR kinase inhibitor designated EKB-569) prevents virus-induced increases in ciliated and goblet cells whereas IL-13 blockade (using $s-I L-13 R \alpha 2-F c)$ exacerbates ciliated cell hyperplasia but still inhibits goblet cell metaplasia. The distinct effects of EGFR and IL-13 inhibitors after viral reprogramming suggest that these combined therapeutic strategies may also correct epithelial architecture in the setting of airway inflammatory disorders characterized by a similar pattern of chronic EGFR activation, IL-13 expression, and ciliated-to-goblet cell metaplasia.
\end{abstract}

\section{Introduction}

Epithelial cell hyperplasia and metaplasia are common consequences of inflammation and may be associated with protective as well as pathogenic outcomes. In the lung, airway epithelial remodeling can be life threatening, since mucous cell metaplasia is the foundation for hypersecretion that can obstruct the airway lumen. Despite the critical nature of this process, little is known about how mucous cell metaplasia develops in the setting of acute or chronic inflammatory disease. Particularly, little is known about the mechanism for what is likely the most common cause of mucous cell metaplasia in the lung, i.e., respiratory viral infection, since previous work has focused on bacterial, allergic, and carcinogenic stimuli. Perhaps because of the paucity of mechanistic information, no effective and specific pharmacologic treatment is currently available to treat epithelial cell metaplasia in general or mucous cell metaplasia in particular.

In this context, recent work on mucous cell metaplasia has often focused on signaling pathways initiated by activation of the IL-13 receptor (IL-13R) and EGFR (also designated ErbB1 and HER1). The experimental role of IL-13R was established when a decoy receptor for IL-13 (soluble IL-13R $\alpha 2-\mathrm{Fc}$ ) was found to inhibit allergen-induced mucous (goblet) cell formation in mice $(1,2)$. These reports have been followed by evidence that IL-13 can directly drive mucin gene expression in airway epithelial cells cultured under physiologic conditions and in vivo (3-6). Moreover, IL-13 is often overexpressed in the setting of mucous cell metaplasia in asthma

Nonstandard abbreviations used: CCSP, Clara cell secretory protein; CLCA, calcium-activated chloride channel; COPD, chronic obstructive pulmonary disease; IL-13R, IL-13 receptor; mTEC, mouse tracheal epithelial cell; PCNA, proliferating cell nuclear antigen; SeV, Sendai virus; SeV-UV, UV-inactivated SeV; z-VAD-fmk, z-Val-AlaAsp fluoromethylketone.

Conflict of interest: The authors have declared that no conflict of interest exists. Citation for this article: J. Clin. Invest. 116:309-321 (2006). doi:10.1172/JCI25167. and chronic obstructive pulmonary disease (COPD) (7-9). The downstream events connecting IL-13R activation to mucin gene expression are incompletely defined, but preliminary work with inhibitors indicates requirements for MEK/ERK, p38 MAPK, and PI3K activation, at least in vitro (5). These effects appear to develop in concert with calcium-activated chloride conductance to promote fluid secretion and consequent mucociliary clearance (10). This function may be connected to expression of a calcium-activated chloride channel (CLCA) that is specific for goblet cells (11). Thus, IL-13 appears to directly stimulate epithelial mucin formation, but the type of epithelial cell that is targeted and the cellular process for mucous cell differentiation remain less certain.

Similar to the case for IL-13, the pathway for EGFR activation leading to mucous cell metaplasia is not well defined. First, altered EGFR expression has been found in humans with asthma (known to exhibit goblet cell metaplasia) and in animal models of asthma, but expression has been variably found on goblet cells as well as other types of airway epithelial cells, e.g., squamous, basal, ciliated, and Clara cells (12-21). This variability is further complicated by uncertainty over the specificity of anti-EGFR antibodies and their capacity to define EGFR activation status. Second, similar to the case for IL-13, animal models often rely on allergen challenge that appears to drive mucin gene expression predominantly in cells that resemble Clara cells by morphology (22-24). These cells express Clara cell secretory protein (CCSP), but tracking cell lineage is complicated by EGFR and IL-13-dependent stimulation of CCSP expression, perhaps in multiple cell types (25). Third, extensions of these studies to signaling mechanisms have often been performed in transformed cell lines $(17,19,26-31)$, and even when primary airway epithelial cells were used, cultures were not fully differentiated under physiologic conditions to a respiratory epithelium $(18,32-34)$. Thus, 1 biochemical scheme from this work suggests that IL-13 stimulation of EGFR signaling leads to 
mucin gene expression (21), but studies of airway epithelial cells under physiologic conditions show that IL-13 fully stimulates goblet cell metaplasia despite EGFR blockade (5). Thus, there is likely a fundamental requirement for EGFR activation in mucociliary differentiation $(5,35)$, but how this requirement may be linked to the modification of epithelial cell growth or differentiation during cytokine stimulation, inflammation, and/or infection still needed to be defined. Fourth, the whole subject of EGFR regulation of cell survival, which appears so critical for neoplasia, has not yet been taken into account in the process of epithelial cell metaplasia during inflammatory disease. Finally, previous approaches concentrate predominantly on the acute phase of epithelial remodeling without addressing chronic goblet cell metaplasia that may be found in hypersecretory airway diseases such as asthma and COPD.

To address these issues, we studied a mouse model of airway epithelial remodeling that is inducible by viral infection and features a delayed but permanent switch to goblet cell metaplasia (36). The observed patterns of acute infection and chronic remodeling were characterized in detail, in particular the dissociation between the acute antiviral response that allows for viral clearance versus the subsequent postviral response manifested by chronic airway hyperreactivity and goblet cell metaplasia $(36,37)$. When we examined the behavior of EGFR signaling in this model, we detected acute activation of EGFR during the epithelial repair phase that was replaced by chronic activation of EGFR localized to ciliated epithelial cells. This chronic activation coincides with ciliated cell hyperplasia without a requirement for ongoing epithelial proliferation. Both ciliated cell hyperplasia and goblet cell metaplasia could be prevented by treatment with a new irreversible inhibitor of EGFR tyrosine kinase. These findings suggested a role for EGFR-dependent signaling pathways in ciliated cell survival, and we subsequently detected and defined such a mechanism that proceeds via $\mathrm{PI} 3 \mathrm{~K} /$ Akt signaling to selectively protect ciliated epithelial cells from apoptosis. However, this mechanism did not readily explain a requirement for EGFR signaling in goblet cell metaplasia until we next detected ciliated cells that appeared to transdifferentiate to goblet cells under pressure from IL-13 stimulation. Thus, in vivo inhibition of IL-13 signaling blocks goblet cell formation but also, by preventing transdifferentiation, further increases the level of ciliated cell hyperplasia. The results thereby provide a new paradigm for chronic goblet cell metaplasia that depends on persistent activation of 2 complementary pathways: EGFR-PI3K signals that protect against ciliated cell apoptosis and IL-13 signals that promote ciliated to goblet cell transdifferentiation. This scheme is consistent with EGFR and IL-13 effects on epithelial cells as well as evidence of ciliated cell EGFR activation, IL-13 production, and goblet cell metaplasia in the epithelium of asthmatic subjects. Therefore, treatment to fully restore normal epithelial behavior in asthma and related hypersecretory conditions such as COPD may need to be directed at combined correction of EGFR- and IL-13-dependent abnormalities in airway epithelial cell survival and differentiation. In that regard, we establish the efficacy of an orally active and irreversible EGFR inhibitor and a soluble IL-13 decoy to prevent these abnormalities in epithelial architecture.

\section{Results}

Persistent activation of EGFR on ciliated epithelial cells. Common human paramyxoviruses often replicate poorly in mice, but mouse parainfluenza virus (Sendai virus; $\mathrm{SeV}$ ) replicates with high efficiency in the bronchiolar mucosa, with consequent induction of immuneresponse gene expression, immune cell infiltration, and damage of the epithelium (37). This host response allows for complete clearance of $\mathrm{SeV}$ by $10-12$ days after inoculation $(36,38)$. The injury is followed by epithelial repair and restoration of normal airway architecture in some mouse strains (see below) but can be followed by long-term (likely permanent) goblet cell metaplasia in C57BL/6J mice that appears at 21 days after inoculation (36). Since EGFR signaling is broadly implicated in epithelial remodeling, we assessed EGFR

A

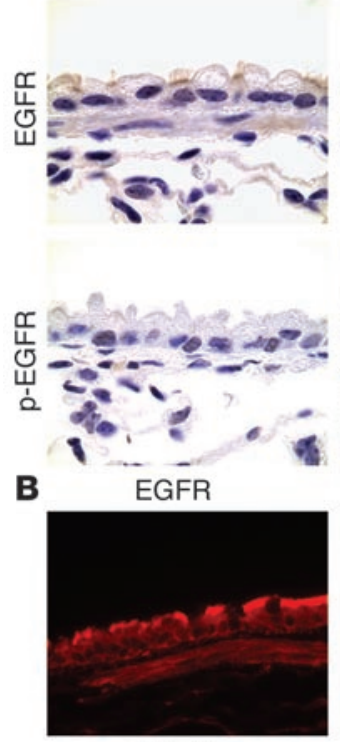

EGFR

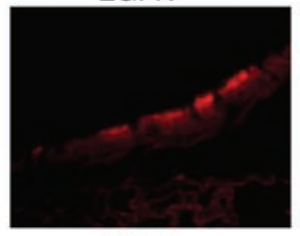

EGFR

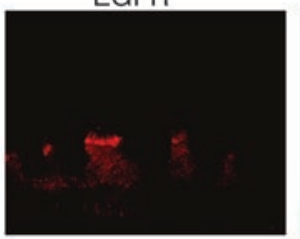

Figure 1

Persistent EGFR activation on ciliated epithelial cells after viral infection. (A) Representative photomicrographs of airway sections from C57BL/6J mice obtained at 21 days after inoculation with $\mathrm{SeV}$ or an equivalent amount of SeV-UV and then immunostained for EGFR and p-EGFR as well as competition by 50 -fold antigen (Ag) excess. Scale bar: $20 \mu \mathrm{m}$. (B) Representative photomicrographs of airway sections obtained from mice at 21 days after inoculation with $\mathrm{SeV}$ and then subjected to immunofluorescent staining for EGFR, $\beta$-tubulin, CCSP, and MUC5AC alone and in combination. Primary anti-EGFR $\mathrm{Ab}$ binding was detected by anti-CY3 $\mathrm{Ab}$ (red fluorescence) while others were detected by anti-FITC Ab (green fluorescence). Scale bar: $20 \mu \mathrm{m}$. Similar results were obtained for mice treated with SeV-UV. 
A $\quad$-Tubulin + CCSP
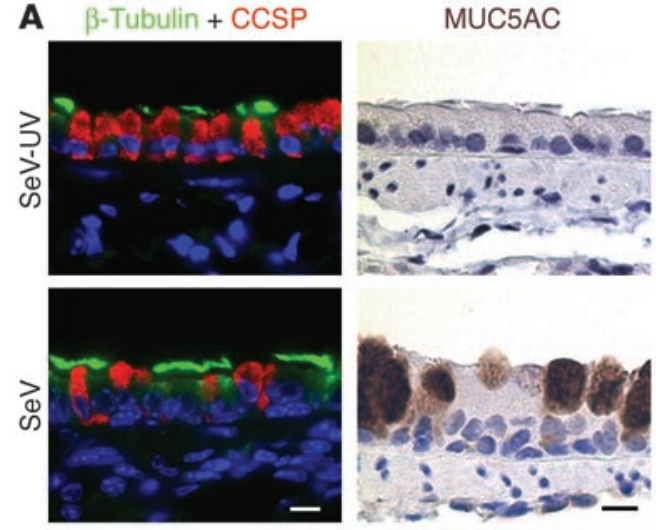

B $\square$ Sev-uv SeV PI day 12

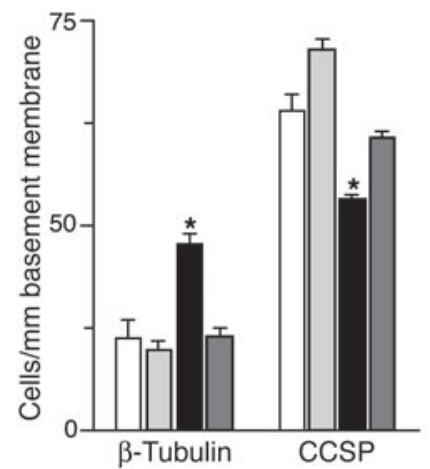

Figure 2

Effect of EGFR blockade on airway epithelial remodeling after viral infection. (A) Photomicrographs of airway sections obtained at 21 days after inoculation with SeV or SeV-UV and then subjected to immunofluorescent staining for $\beta$-tubulin (green fluorescence) and CCSP (red fluorescence) and immunostaining for MUC5AC. Immunostaining with nonimmune IgG gave no signal above background (data not shown). Scale bars: $20 \mu \mathrm{m}$. (B) Corresponding quantitative data for conditions in A plus postinoculation day 12 (PI day 12) without treatment and day 21 after treatment with EKB-569 for days 10-21 after inoculation. Values represent mean \pm SEM. *Significant difference from SeV-UV control.

behavior in mouse airway epithelium in this model. Western blot analysis indicated that anti-EGFR and anti-phospho-EGFR (antip-EGFR) antibodies specifically recognized the receptor in airway tissue samples (data not shown). Immunostaining of airway tissue with anti-EGFR antibody indicated that EGFR expression was predominantly localized to the apical membrane of ciliated epithelial cells, although other cell types (e.g., basal cells and airway smooth muscle cells) were also weakly immunostained (Figure 1A). No significant difference was observed in the pattern or the level of anti-EGFR immunostaining between mice infected with $\mathrm{SeV}$ and control mice that were inoculated with UV-inactivated $\mathrm{SeV}$ (SeV-UV). In contrast, immunostaining for p-EGFR (using an anti-p-EGFR antibody that recognizes phosphorylated $\left.\mathrm{Tyr}^{845}\right)$ indicated that levels of activated EGFR were persistently increased at 21 days after inoculation with $\mathrm{SeV}$ compared with uninoculated or SeV-UV-inoculated control mice. Similar to the pattern for EGFR expression, p-EGFR was also localized mainly to the apical surface of ciliated epithelial cells, but in this case, apical cell staining was also accompanied by corresponding nuclear staining in this same ciliated cell population (Figure 1A).
Other cell types (e.g., basal cells) were also weakly immunostained in nuclear and cytosolic locations. These findings are consistent with reports of nuclear translocation of activated EGFR (39). This pattern of immunostaining indicated that the initial EGFR antibody recognizes predominantly the unphosphorylated receptor. For both antibodies, immunostaining was completely abolished by preabsorption with corresponding antigen. In addition, normal rabbit IgG was used as a negative isotype control and showed no significant signal above background. In further support of EGFR expression localized predominantly to ciliated epithelial cells, double labeling and immunofluorescence detected by laser scanning confocal microscopy indicated that EGFR colocalized with a marker for ciliated epithelial cells (i.e., $\beta$-tubulin) but not with markers for Clara cells (i.e., CCSP) or goblet cells (i.e., MUC5AC) in mouse airways (Figure 1B).

This pattern of EGFR immunostaining found in mice was similar to the one in human subjects. In particular, EGFR expression was also localized to the apical cell membrane of ciliated epithelial cells in normal and asthmatic subjects, and p-EGFR was increased in asthmatic subjects that also manifested goblet cell metaplasia (Supplemental Figure 1; supplemental material available online with this article; doi:10.1172/JCI25167DS1). Expression of p-EGFR was similarly localized to the apical portion of ciliated epithelial cells, and expression was accompanied by corresponding nuclear staining in the same ciliated cells. Additional, albeit weaker, p-EGFR immunostaining was also present on basal cells in both normal and asthmatic subjects. This finding was also consistent with previous reports of EGFR expression in this basal cell population $(12,15$, $18,19)$. The present pattern of EGFR localization to the apical and ciliary regions of ciliated epithelial cells is consistent with observations in developing lung and other sites (40-43). Others report basolateral localization of EGFR in some epithelial tissues (e.g., gut and kidney) $(44,45)$ and in airways (46); we find expression at this location as well but without any predilection for ciliated cells. In either case, the consistent finding of EGFR and p-EGFR expression on ciliated epithelial cells in mouse and human airways led us to continue these studies in a mouse model of asthma, where experimental conditions and genetic background are more completely controlled and more extensive lung sampling is possible.

EGFR as a critical component in epithelial remodeling. To define a functional role for persistent EGFR signaling on ciliated epithelial cells, lung sections were subjected to immunostaining with markers for ciliated epithelial cells, Clara cells, and goblet cells. Quantitative analysis of cell types found in the airway epithelium indicated that SeVinfected mice developed increases in ciliated and goblet cells and concomitant decreases in Clara cells at day 21 (but not by day 12) after inoculation compared with control mice inoculated with SeV-UV (Figure 2). We next determined whether EGFR signaling was necessary for these observed changes in epithelial architecture. For these studies, we used a new irreversible EGFR inhibitor (EKB-569) that selectively inhibits EGFR signaling in airway epithelial cells in vitro (Supplemental Figure 2). To achieve blockade in vivo, we administered EKB-569 orally each day from postinoculation day 10 (so as not to interfere with viral clearance or epithelial repair) through day 21 (when the remodeling response developed). Under these treatment conditions, EKB-569 also blocked EGFR signaling in vivo (Supplemental Figure 2). Moreover, when provided in this way, EGFR inhibitor treatment also helped to correct all 3 aspects of epithelial remodeling. Specifically, we observed complete blockade of ciliated cell increases and Clara cell decreases and partial but significant inhibition of goblet cell metaplasia (Figure 2B). EKB-569 treatment had 
A

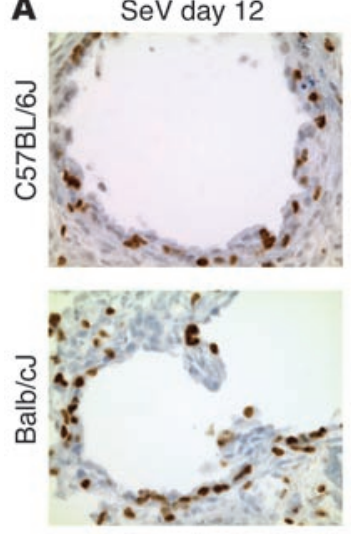

C $\quad \mathrm{SeV}$ day 12
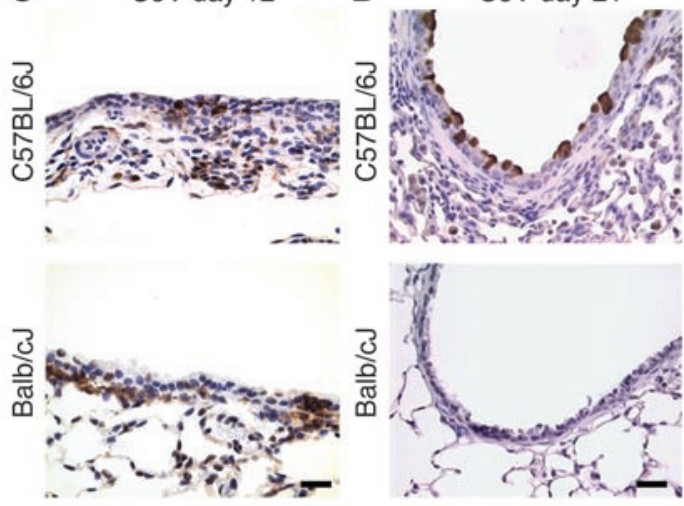

SeV day 21
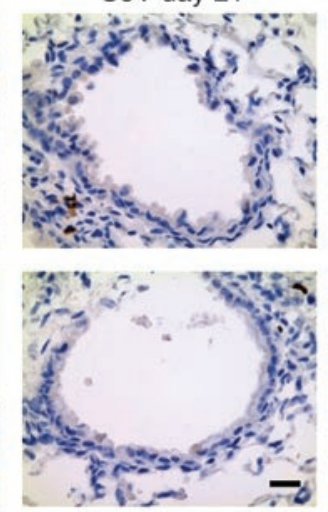

D

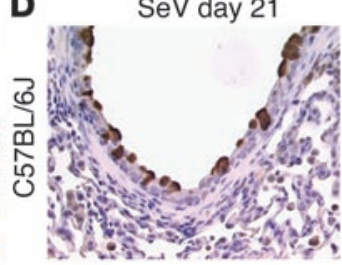

B

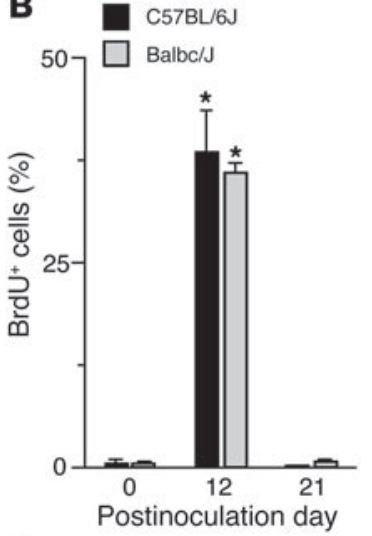

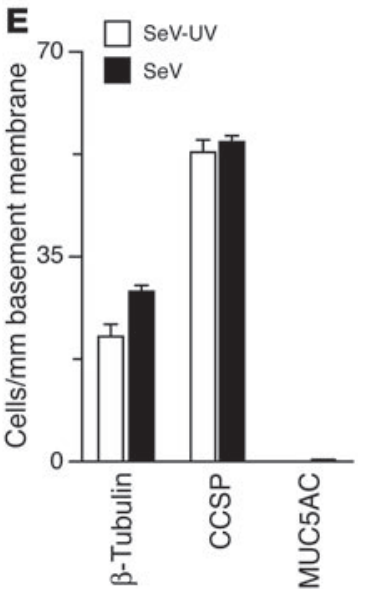

\section{Figure 3}

Airway epithelial remodeling without cellular proliferation in genetically susceptible mice. (A) Representative photomicrographs of airway sections obtained from C57BL/6J and Balb/cJ mice at indicated days after inoculation with $\mathrm{SeV}$ and subjection to immunostaining for BrdU. (B) Corresponding quantitative data for conditions in A. (C) Representative photomicrographs of airway sections from indicated conditions, immunostained for p-EGFR. (D) Representative photomicrographs of airway sections from indicated conditions, immunostained for MUC5AC. (E) Quantitative morphometry for airway sections that were obtained from Balb/cJ mice at 21 days after inoculation with SeV or SeV-UV and subjection to immunostaining for $\beta$-tubulin, CCSP, and MUC5AC. For $\mathbf{B}$ and $\mathbf{E}$, values represent mean \pm SEM. *Significant difference from day 0 or SeV-UV control. Scale bars: $20 \mu \mathrm{m}$. no effect on the total number of airway epithelial cells (cytokeratinstaining cells were $133 \pm 3$ after vehicle and $137 \pm 5 / \mathrm{mm}$ basement membrane after drug treatment on postinoculation day 21), consistent with compensatory changes in other epithelial cell (e.g., basal and Clara cell) populations. Based on immunohistochemical data showing localization of EGFR and $\beta$-tubulin expression together in the same ciliated cell population, we expected that EGFR blockade might influence ciliated cell hyperplasia. However, the effect of interrupting EGFR signals on goblet cell (or Clara cell) levels was unexpected based on the relative absence of activated EGFR expression on either of these cell types. Further experiments were therefore designed to better understand the mechanisms underlying the role of EGFR in chronic epithelial remodeling.

We reasoned that epithelial hyperplasia could either be a result of increased proliferation or decreased cell death. We therefore initially looked for evidence of increased proliferation in mice with epithelial remodeling. As noted previously, there was transient epithelial proliferation (marked by BrdU labeling) during days 5-12 after infection (Figure 3, A and B, and ref. 47). The same pattern of immunostaining was found for Ki-67 and proliferating cell nuclear antigen (PCNA) proliferation markers (data not shown). This proliferative response likely allows for replacement of host cells that suffer direct cytopathic effects and immune-mediated cell death in the wake of viral replication (38). Not surprisingly, this repair phase is accompanied by EGFR activation in epithelial cells (generally basal cells) as well as subepithelial (likely immune) cells (Figure 3C). However, by postinoculation day 21 , there was no longer evidence of an ongoing proliferative response, since cellular proliferation was no different than in noninoculated control mice (Figure 3, $\mathrm{A}$ and $\mathrm{B}$ ). Moreover, this replacement phase (marked by BrdU uptake and EGFR activation in the basal cell compartment) was the same in a strain of mice (Balb/cJ) that does not develop long-term epithelial remodeling (Figure 3, A-E). Thus, this transient proliferative response could not account for the subsequent long-term remodeling that was found only in genetically susceptible (C57BL/6J) mice. Moreover, the lack of an ongoing epithelial proliferative response suggested that ciliated cell hyperplasia might reflect a selective increase in EGFR-dependent cell survival based on suppression of cell death in this subpopulation of epithelial cells.

EGFR signaling and ciliated cell survival in culture. To determine whether EGFR provides necessary survival signals to ciliated epithelial cells, we next analyzed EGFR blockade in tissue culture where macrophage clearance would not obscure detection of apoptotic cells and where signaling events could be better defined. Initial experiments aimed to determine whether EGFR was localized to ciliated epithelial cells in culture as was found in vivo. We therefore reconstituted the epithelial system in vitro using air-liquid interface cultures of airway epithelial cells harvested from mouse trachea. In this system, ciliated ( $\beta$-tubulin-positive) cells represented $45 \% \pm 1 \%$ of the total cell population, a level that was similar to normal mouse airways (36\% for large-sized airways) and to values for mouse tracheal specimens reported previously (48). As was the case in vivo, the ciliated epithelial cells in culture exhibited constitutive expression of EGFR and p-EGFR along the apical cell membrane; p-EGFR was found in this location as well as a nuclear one following activation by ligand (Figure 4A and data not shown). Others reported 
A

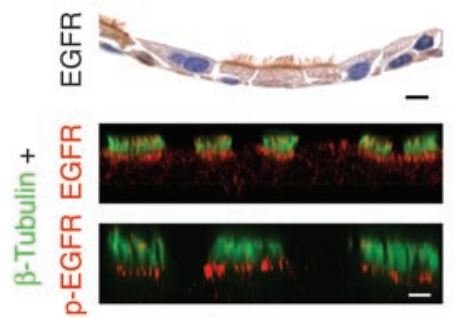

B

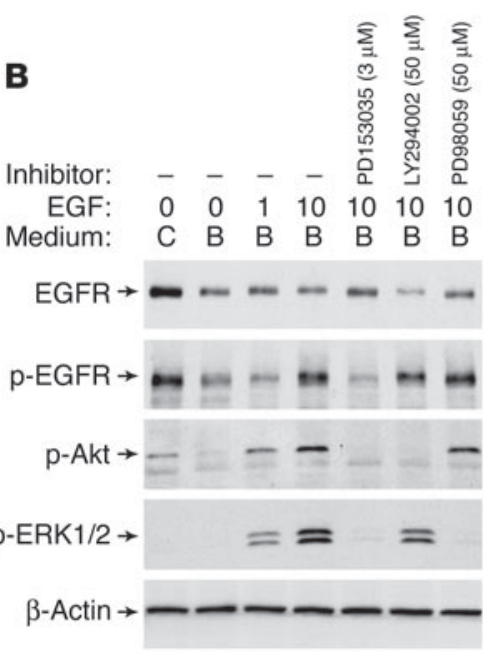

C
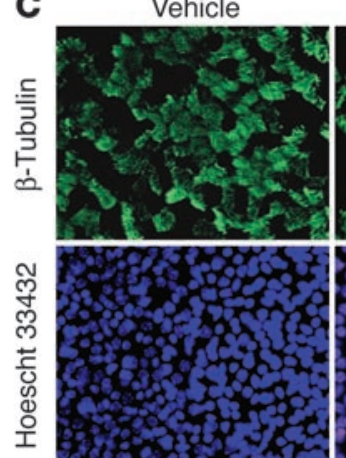

D

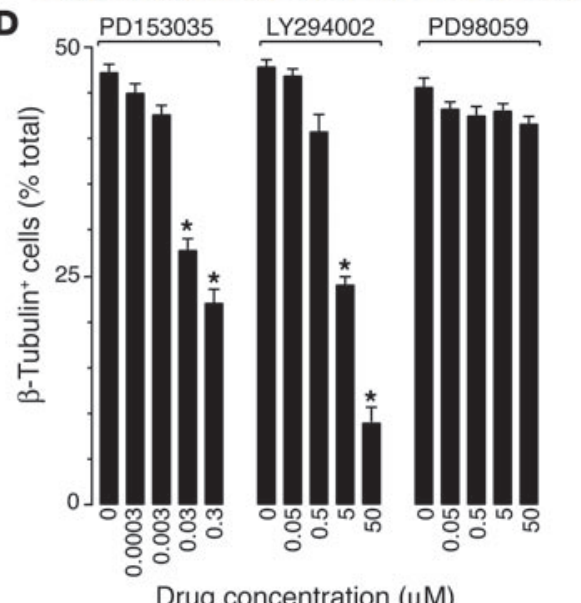

PD153035 (0.3 $\mu \mathrm{M})$
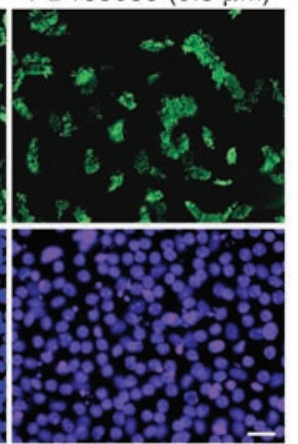

Drug concentration $(\mu \mathrm{M})$

\section{Figure 4}

Effect of EGFR signaling pathways on ciliated epithelial cell death in culture. (A) Representative photomicrographs of airway epithelial cell cultures placed under air-liquid interface conditions for 10 days followed by immunostaining for EGFR (top panel) or double immunofluorescence and confocal microscopy for $\beta$-tubulin and either EGFR (middle panel) or p-EGFR (bottom panel). Scale bars: $20 \mu \mathrm{m}$. (B) Western blot analysis of mTEC cultures that were placed in basic medium for 1 day and then treated with EGF ( 1 or $10 \mathrm{ng} / \mathrm{ml}$ ) for 10 minutes with or without concomitant inhibitor. Each inhibitor was added at maximal effective concentrations to the lower chamber for 6 hours and the upper chamber for 2.5 hours before addition of EGF to both chambers. For each condition, cell lysates were blotted against anti-EGFR, p-EGFR, p-Akt, or p-ERK1/2 Ab, and Ab binding was detected by enhanced chemiluminescence. (C) Representative photomicrographs of mTEC cultures that were treated with vehicle or PD153035 $(0.3 \mu \mathrm{M})$ for 7 days at $37^{\circ} \mathrm{C}$ and subjected to immunofluorescent staining for $\beta$-tubulin IV and Hoescht 33432. Scale bar: $20 \mu \mathrm{m}$. (D) Quantitative analysis of $\beta$-tubulin staining cells (expressed as a percentage of total Hoechst staining cells) without and with treatment with PD153035, LY294002, and PD98059, given at the indicated doses for 7 days. *Significant difference versus $0 \mu \mathrm{M}$. that EGFR may also be localized to the basolateral cell membrane in cultured airway epithelial cells (46), but any differences could depend on culture conditions, receptor heterogeneity that influences recognition by different antibodies, or receptor abundance that may influence apical versus basolateral localization (49).

We next defined the role of EGFR signaling in ciliated epithelial cell growth and survival using treatment with selective inhibitors. Initial experiments to validate inhibitor specificity used cultures that were first removed from complete medium and then stimulated with EGF to maximize EGFR-dependent signals. Under these conditions, we found that EGFR tyrosine kinase inhibition with PD153035 blocked all downstream signals, while PI3K inhibition with LY294002 blocked phosphorylation of Akt, and MEK1/2 inhibition with PD98059 blocked phosphorylation of ERK1/2 (Figure 4B). The next experiments determined the effect of these EGFR signals on ciliated cell survival. We found that treatment with PD153035 caused a dose-dependent loss of ciliated cells out of proportion to the consequent decrease in total epithelial cells (Figure 4C). Similar results were obtained with another EGFR-specific inhibitor, AG1478 (data not shown). Recognizing that EGFR activation triggers several downstream signaling pathways, we next treated mouse tracheal epithelial cell (mTEC) cultures with inhibitors of PI3K and MEK1/2 and found that only treatment with LY294002 caused a similar loss of ciliated epithelial cells (Figure 4D). Since this culture system does not exhibit significant cell growth at high density, it appeared likely that the loss of ciliated epithelial cells was due to decreased cell survival.

Accordingly, we next tested whether blockade of EGFR signaling led to concordant changes in the level of apoptosis. In parallel with loss of ciliated epithelial cells, we also observed rapid activation of caspase- 3 and TUNEL-positive cells (within 6 hours) in the same pattern that we had observed for cell loss, i.e., when EGFR or PI3K but not MEK1/2 signaling was blocked (Figure 5A). In this setting, TUNEL-positive cells were undergoing apoptosis, since this process was blocked by treatment with the caspase-inhibitor z-Val-Ala-Asp fluoromethylketone (z-VAD-fmk) (Figure 5B) and was associated with caspase-3 and caspase-9 cleavage/activation (Figure 5C) and loss of mitochondrial membrane potential (Figure 4D). These results therefore define an EGFR signaling pathway that protects against ciliated cell apoptosis via selective PI3K signaling to downstream factors that prohibit mitochondrial dysfunction and consequent programmed cell death. As discussed below, the findings stand in some contrast to reports of EGFR and other receptor signals to ERK1/2 that prevent cell death under other circumstances $(38,50,51)$.

EGFR signaling and goblet cell metaplasia in vitro and in vivo. As noted above, the actions of EGFR signaling on ciliated cells did not readily explain the effect of EGFR blockade on goblet cell metaplasia in vivo. In particular, selective EGFR expression and consequent survival function on ciliated cells could account for inhibition of ciliated cell hyperplasia but could not account directly for blockade of goblet cell metaplasia as well. Despite the low levels of EGFR expression on goblet cells, we next questioned whether EGFR might still have a similar functional effect on goblet cell survival. To test this possibility, we took advantage of concomitant studies that defined IL-13 dependence of goblet cell metaplasia after viral infection (E.Y. Kim and M.J. Holtzman, unpublished observations). This effector pathway therefore overlaps with that established in studies of mucin production after allergen challenge $(1,2)$. In addition, we recognized the capacity of IL-13 treatment to stimulate goblet cell formation in 
A
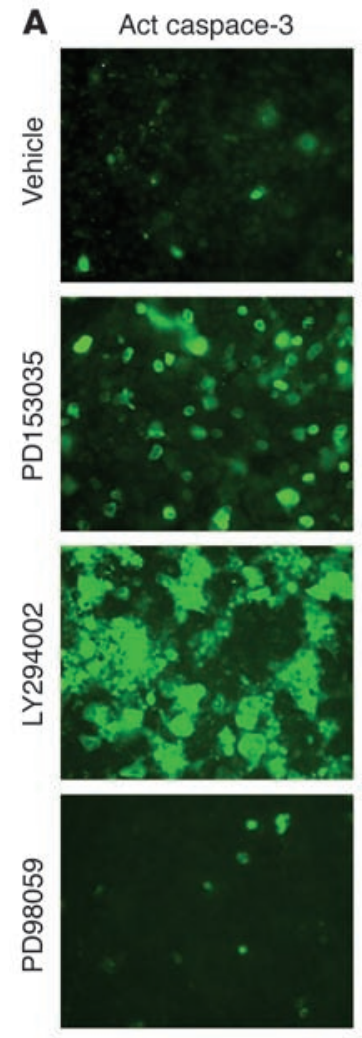

TUNEL
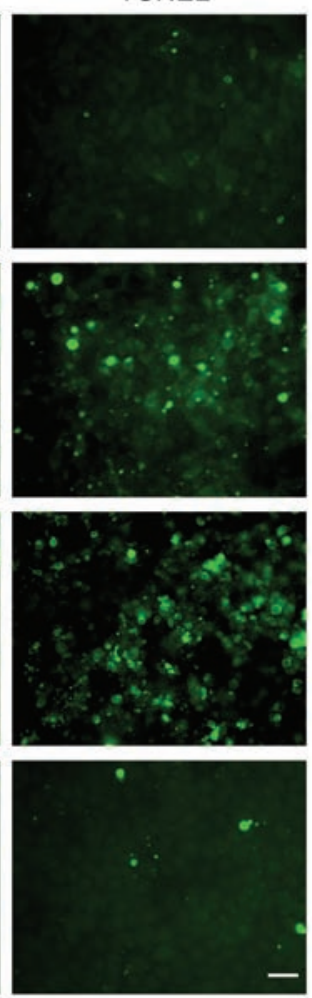

B
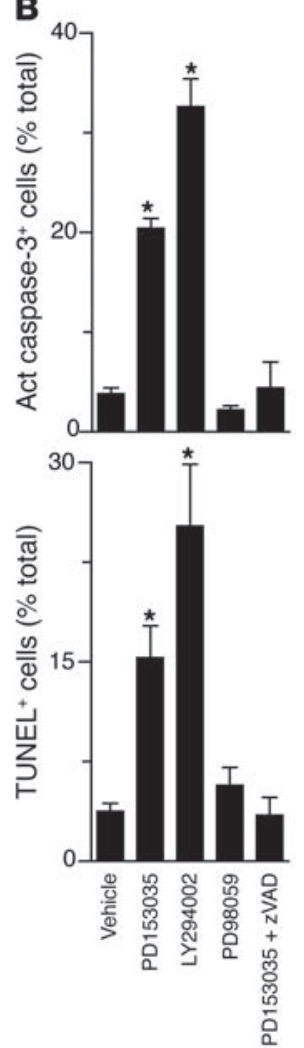

C

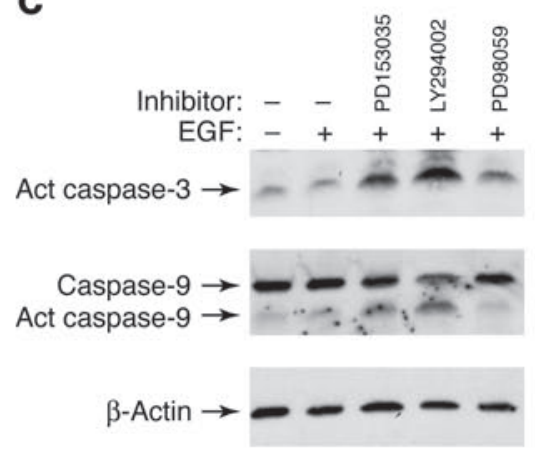

D

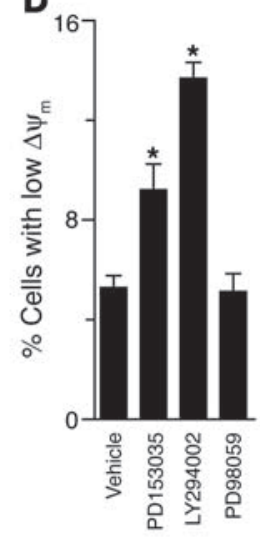

\section{Figure 5}

Effect of EGFR signaling pathways on apoptosis in airway epithelial cell cultures. (A) Representative photomicrogaphs of mTEC cultures that were treated with vehicle, PD153035 (0.3 $\mu \mathrm{M})$, LY294002 (50 $\mu \mathrm{M})$, and PD98059 (50 $\mu \mathrm{M})$ for 3 days at $37^{\circ} \mathrm{C}$ and then subjected to immunofluorescent staining for cleaved fragment of active caspase-3 (act caspase-3) or TUNEL reaction. Scale bar: $20 \mu \mathrm{m}$. (B) Quantitative analysis of information in $\mathbf{A}$ for active caspase-3 staining cells (expressed as percentages of total Hoechst staining cells), using treatment conditions from A as well as PD15305 plus z-VAD-fmk (100 $\mu \mathrm{M})$. (C) Immunoblot analysis of active caspase-3 and caspase-9 in cell lysates from mTEC cultures using treatment conditions from A. Anti-caspase-9 antibody recognizes precursor (caspase-9) and the cleaved fragment of active caspase-9. (D) Flow cytometric analysis of JC-1 staining of mTEC cultures using treatment conditions from $\mathbf{A}$. Values represent percentages of cells with decreased mitochondrial membrane potential $(\Delta \Psi \mathrm{m})$ detected by shift from FL2 to FL1. For $\mathbf{B}$ and $\mathbf{D}$, values represent mean \pm SEM. *Significant difference from vehicle alone.

airway epithelial cells cultured from guinea pigs and humans (3-5) as well as mice (J.D. Morton and M.J. Holtzman, unpublished observations). Cultured mTECs were therefore treated with IL-13, and the subsequent development of goblet cells was marked by expression of MUC5AC. Cell death was tracked with activation of caspase-3, since the procedure for the TUNEL reaction appears to decrease mucin content. In contrast to ciliated cells, we found that goblet cells did not exhibit increased rates of cell death in response to EGFR inhibition (Figure 6A). Quantifying the level of active caspase-3 cells in MUC5AC-positive versus MUC5AC-negative populations indicated that the level of apoptosis was similar in goblet cells with or without EGFR blockade, whereas the nongoblet cells (i.e., ciliated epithelial cells) exhibited significant caspase-positive staining under these treatment conditions (Figure 6B). Moreover, the level of nongoblet cell death was similar with or without IL-13 treatment, indicating that the death pathway in ciliated cells is not influenced by IL-13dependent actions on goblet cell formation.

Since EGFR blockade caused no effect on goblet cell survival in vitro, we reasoned that the potent effects of EGFR blockade on goblet cell metaplasia in vivo might be downstream of EGFR blockade of ciliated cell hyperplasia. Support for that possibility was obtained when we found that IL-13 treatment led to the development of cells that transiently shared characteristics of ciliated and goblet cells. Thus, electron microscopy of mTEC cultures provided evidence of a subset of cilia-goblet cells with preservation of cilia and the gradual development of mucous granules under the influence of IL-13 (Figure 7). These transitional cells were most prominent early (1-2 days) after initiation of IL-13 treatment, while mature goblet cells without cilia were most abundant at later times ( 5 days) after treatment. The morphologic characteristics of cilia-goblet cells under these conditions appear quite similar to ciliated cells containing mucous granules found by electron microscopy in airways of allergen-challenged mice (23).

Since airway epithelial cultures were established under conditions that required IL-13 treatment to promote goblet cell formation in an environment that would otherwise produce ciliated cells, these ciliagoblet cells were likely being redirected by IL-13 to transdifferentiate from a ciliated to goblet cell phenotype. The possibility that similar transdifferentiation also developed in vivo was next confirmed in sections taken from mice exhibiting goblet cell metaplasia after inoculation with $\mathrm{SeV}$. Confocal microscopy indicated that, while the majority of ciliated or goblet cells expressed either $\beta$-tubulin or 
A
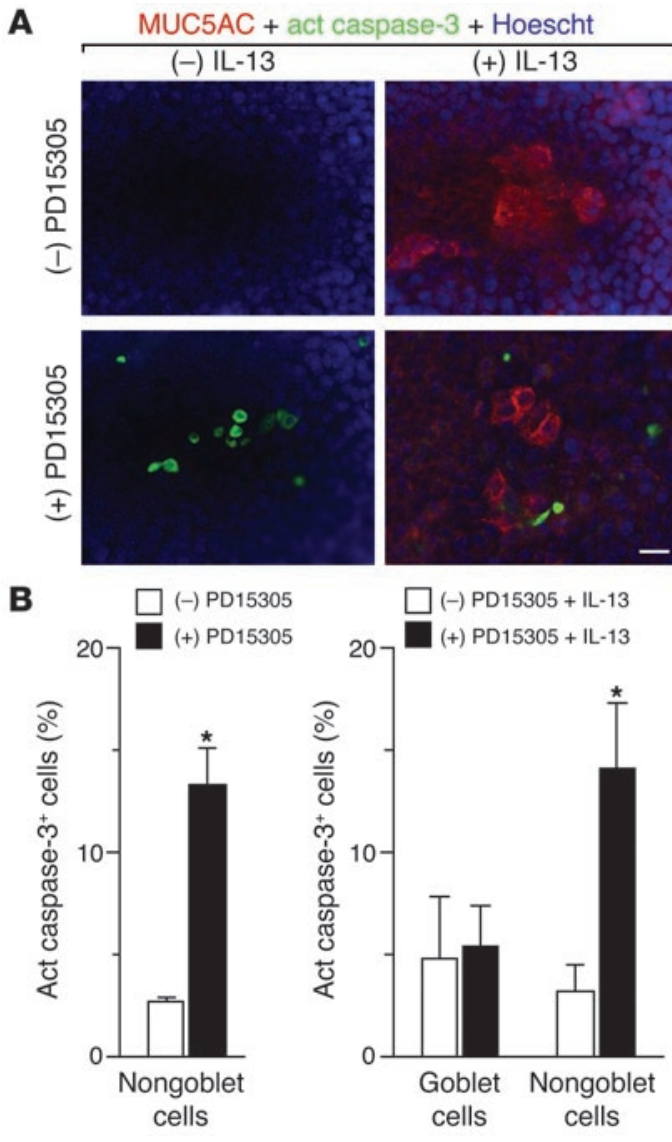

MUC5AC, respectively, there was a subpopulation of epithelial cells that expressed both $\beta$-tubulin and MUC5AC (Figure 8A). Similarly, confocal images also indicated that, in general, ciliated but not goblet cells expressed EGFR, but there was an additional subpopulation of cells that expressed both EGFR and MUC5AC (Figure 8B). In each case, multiple confocal sections along the $z$ axis and $3 \mathrm{D}$ reconstruction were used to confirm colocalization within a single cell. The subpopulation expressing MUC5AC and $\beta$-tubulin and or MUC5AC and EGFR appeared to be in transition, since they did not often reach their characteristic shape and position at the lumenal surface of the mucosal epithelial layer as was found for mature goblet cells. In addition, in these transitioning cells, the mucous granules were often localized in a more basal compartment of the cells versus a more apical location for fully differentiated goblet cells. This morphologic behavior also suggests that these cilia-goblet cells represent goblet cell precursors. As noted previously for allergen-induced goblet cell metaplasia, we also detected a subpopulation of epithelial cells with coexpression of CCSP and MUC5AC (Figure 8C) at levels comparable to detection of cilia-goblet cells (Figure 8E).

We next aimed to establish whether IL-13 also promotes cilia to goblet cell formation in vivo as we had observed in vitro. For these experiments, we took advantage of a recombinant soluble IL-13R $\alpha 2 \mathrm{Fc}$ fusion protein (designated sIL-13R $\alpha 2-\mathrm{Fc}$ ) that acts as a decoy receptor to specifically block IL-13 action when delivered to mice $(1,2)$. Treatment conditions were chosen to be similar to those used for EGFR blockade, so treatment extended from day 12 to 21 after viral inoculation. This time frame also coincides with the induction of IL-13, mCLCA3, and MUC5AC gene expression in concert with the

\section{Figure 6}

Effect of EGFR inhibition on ciliated but not goblet cell death in vitro. (A) Representative photomicrographs of mTEC cultures treated with or without IL-13 (100 $\mathrm{ng} / \mathrm{ml}$ for 5 days) and with or without subsequent PD153035 (0.3 $\mu \mathrm{M}$ for 3 days) and subjected to immunofluorescent staining for MUC5AC (red) and active caspase-3 (green) as well as counterstaining with Hoescht dye (blue). Scale bar: $20 \mu \mathrm{m}$. (B) Corresponding quantitative data for $A$. Values represent mean \pm SEM for percentage of active caspase- $3^{+}$goblet cells (number of MUC5 $\mathrm{AC}^{+}$active caspase- $3^{+}$cells $\times 100 /$ number of MUC5AC+ cells) and active caspase$3^{+}$nongoblet cells (total number of active caspase- $3^{+}$cells $\times 100 /$ total Hoescht staining cells). *Significant difference from vehicle control.

development of goblet cell metaplasia (Figure 8D). Under these conditions, we found that sIL-13R $\alpha 2-\mathrm{Fc}$ treatment was highly effective in preventing virus-induced goblet cell metaplasia (Figure 8E). However, in some contrast to EGFR blockade, sIL-13Ra2 treatment also caused a further increase in the level of ciliated cell hyperplasia (consistent with a block in their movement to goblet cells) and no change in Clara cell levels (consistent with the possibility that goblet cell formation derives at least in part from ciliated cell rather than Clara cell populations). We cannot fully exclude the possibility that other cellular sources (e.g., Clara cells or basal cells) may also contribute to goblet cell metaplasia in this setting, but the close match of ciliated cell increase to goblet cell decrease after IL-13 blockade suggests that transdifferentiation of the ciliated cell population is a significant pathway for goblet cell metaplasia under these conditions. Indeed, together with previous and present evidence of Clara cell expression of mucin genes, the present results may simply provide evidence of additional plasticity of epithelial cell differentiation.

In a final 2 sets of experiments, we again extended our findings from mice to studies of human subjects. In the first set of experi-

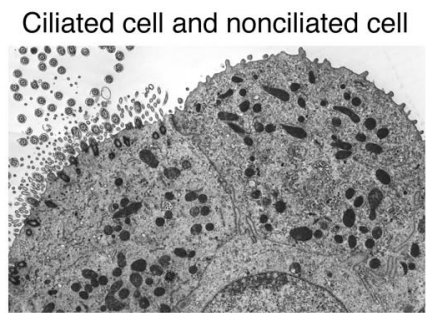

Late cilia-goblet cell

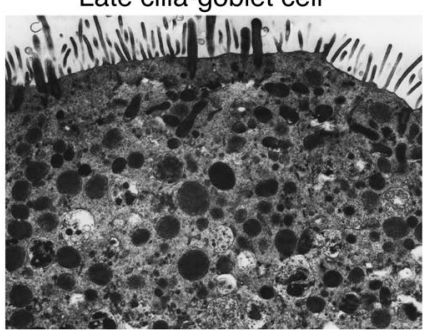

Figure 7

Identification of IL-13-dependent ciliated-to-goblet cell transdifferentiation in vitro. Representative transmission electron micrographs are shown for cultured mTECs before treatment (upper left panel) and then after treatment with IL-13 (100 ng/ml for 2 days at $37^{\circ} \mathrm{C}$; all other panels). Early cilia-goblet cells are identified with cilia that are visible on the surface of cells that also contain a few mucous granules, late cilia-goblet cells exhibit greater numbers of mucous granules in the cytoplasm, and mature goblet cells contain characteristic mucous granules with no cilia. 
A
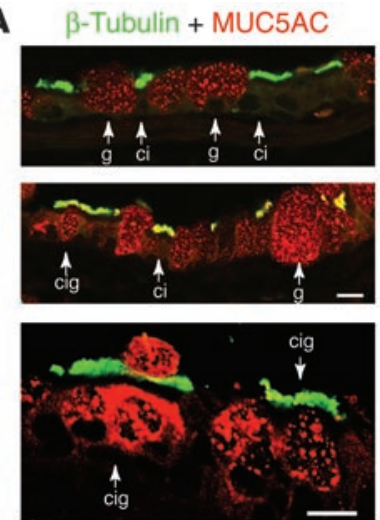

B
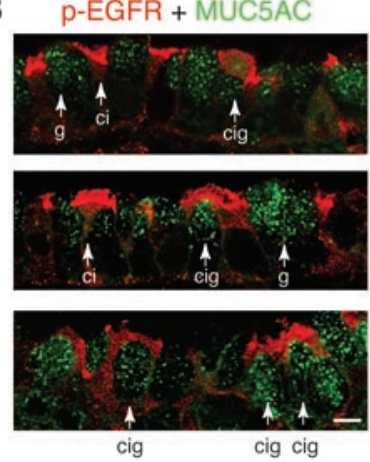

cig

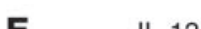

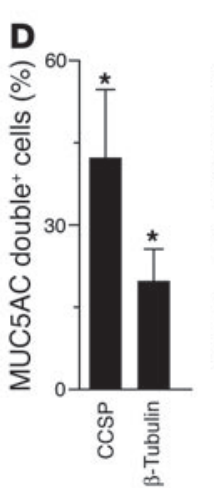
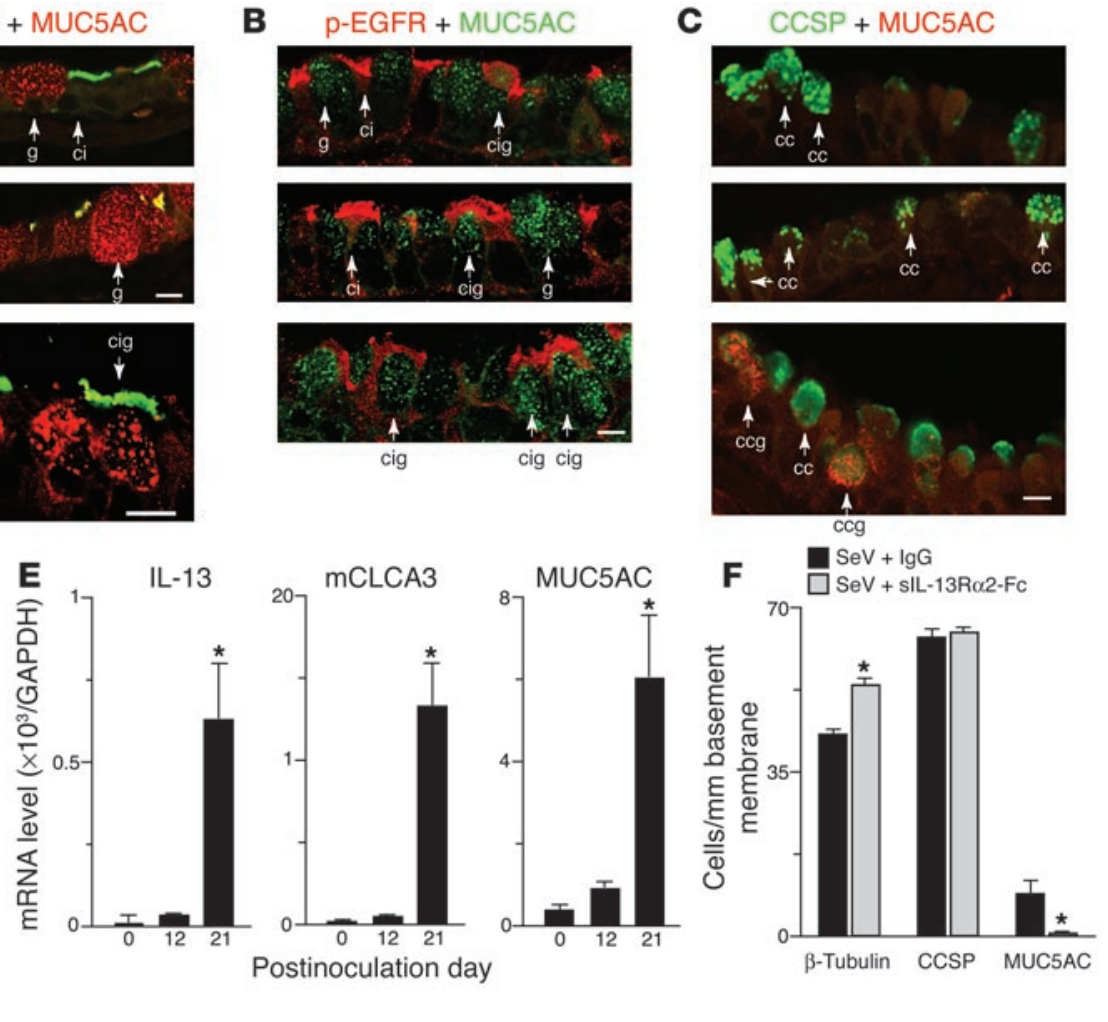

Figure 8

Identification and blockade of cilia-to-goblet cell transdifferentiation in vitro and in vivo. (A) Representative photomicrographs of airway sections obtained from mice at 21 days after SeV inoculation and subjected to confocal immunofluorescence microscopy for $\beta$-tubulin (green) and MUC5AC (red). Arrows indicate ciliated cells staining for $\beta$-tubulin (ci), goblet cells staining for MUC5AC (g), and cells staining for both $\beta$-tubulin and MUC5AC (cig). (B) Representative photomicrographs of airway sections obtained as in A but immunostained for p-EGFR (red) and MUC5AC (green). Arrows indicate ciliated cells staining for p-EGFR (ci), goblet cells staining for MUC5AC (g), and cells staining for both p-EGFR and MUC5AC (cig). (C) Representative photomicrographs of airway sections obtained as in A but immunostained for CCSP (green) and MUC5AC (red). Arrows indicate cells staining for CCSP (cC) or CCSP and MUC5AC (ccg). Scale bars: $20 \mu \mathrm{m}$. (D) Quantitative analysis of MUC5AC-expressing cells that also immunostained for CCSP or $\beta$-tubulin. (E) Real-time PCR analysis of lung IL-13, mCLCA3, and MUC5AC mRNA levels corrected for GAPDH control level at indicated times after SeV inoculation. (F) Quantitative analysis of $\beta$-tubulin, CCSP, and Muc5AC immunostaining in mice inoculated with SeV and treated with sIL-13Ro2-Fc or control IgG on days 12, 14, 17, and 20 after inoculation. Values represent mean \pm SEM *Significant difference from corresponding SeV-UV control for $\mathbf{D}$ and $\mathbf{E}$ or IgG treatment for $\mathbf{F}$.

ments, we analyzed airway tissue from a group of COPD patients that exhibited markedly increased levels of goblet cells in the airway and provided adequate lung tissue for analysis at the time of lung transplantation. By applying the same immunostaining protocol for immunofluorescence and confocal microscopy as for the mouse model, we found that sections of lung explants from COPD patients also exhibited evidence of $\beta$-tubulin-MUC5AC coexpression in a subset of airway epithelial cells (Figure 9A). We did not detect lumenal staining for $\beta$-tubulin in human (or mouse) airways, consistent with the proposal that cilia may be processed by endosomal degradation rather than shedding. As noted previously (52), CCSP-MUC5AC coexpression was also found in a subset of epithelial cells. In the second set of experiments, we again applied the strategy that we used for mouse studies and analyzed the behavior of human airway epithelial cells in air-liquid interface culture conditions without or with IL-13. In this case, we found that airway epithelial cells cultured from COPD patients led to the development of a subset of cells that coexpressed $\beta$-tubulin and MUC5AC under the influence of IL-13. As noted previously, $\beta$-tubulin is localized within the basal bodies of ciliated cells (53) and so provides even closer colocalization with
MUC5AC found in mucous granules. The same pattern of IL-13induced coexpression of ciliated and goblet cell markers was found in airway epithelial cells cultured from otherwise healthy lung transplant donors in response to IL-13, even within the first day of IL-13 treatment (Figure 9C). As we did for the studies of mouse and human tissue, we examined multiple confocal images along the $z$ axis and $3 \mathrm{D}$ reconstruction to establish colocalization of ciliated and goblet cell markers within a single cell. Thus, similar to our experience for EGFR activation in human subjects, we found that the downstream mechanism for goblet cell metaplasia found in the mouse model, i.e., IL-13-driven ciliated-to-goblet cell transdifferentiation, appears to have a counterpart in hypersecretory human disease.

\section{Discussion}

The present report provides initial evidence that transient viral bronchiolitis causes a long-term switch to ciliated cell hyperplasia as well as goblet cell metaplasia and that the hyperplastic ciliated cell population exhibits persistent EGFR activation without proliferation. This finding came in some contrast to the fate of ciliated cells in other lung injury models where this cell population is 


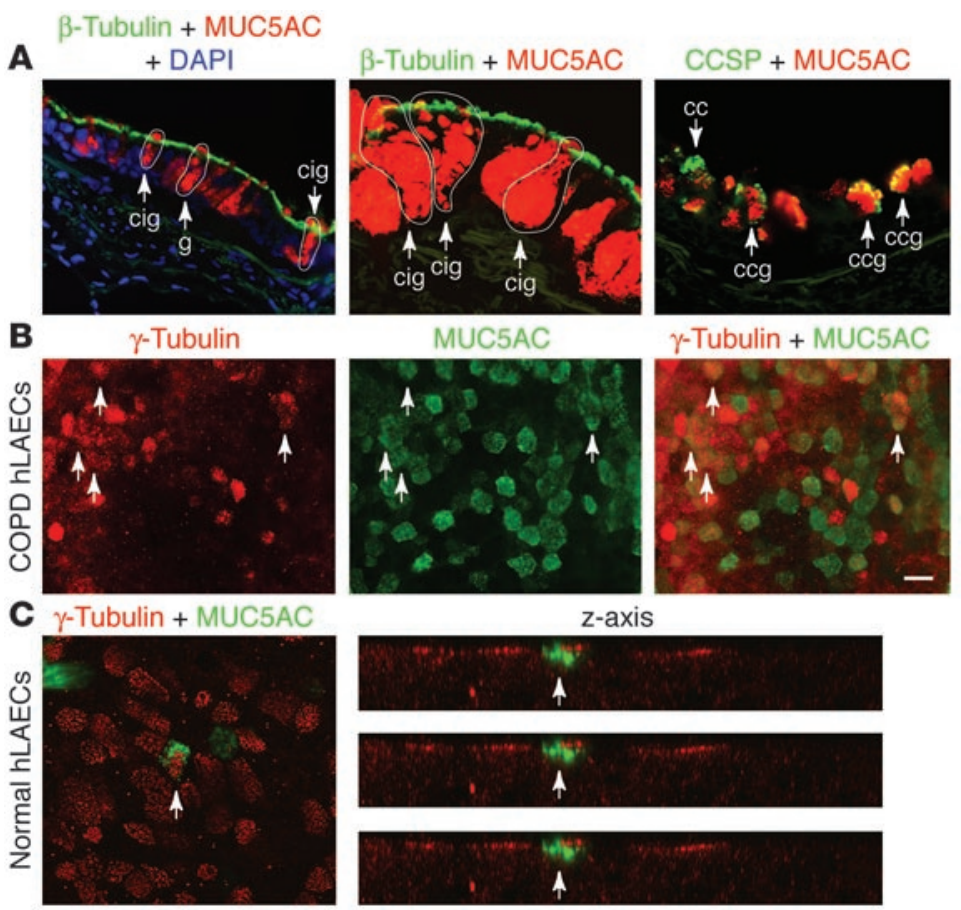

\section{Figure 9}

Evidence of cilia-to-goblet cell transdifferentiation in human epithelial cells in vivo and in vitro. (A) Representative photomicrographs from lung sections obtained from COPD patients and immunostained for $\beta$-tubulin and MUC5AC, counterstained with DAPI, and viewed with immunofluorescence microscopy (left panel) or immunostained for $\beta$-tubulin and MUC5AC or CCSP and MUC5AC and viewed with laser confocal scanning microscopy (middle and right panels). Arrows and outlines indicate goblet cells that express MUC5AC (g), Clara cells that express CCSP (cc), cilia-goblet cells that coexpress $\beta$-tubulin and MUC5AC (cig), and goblet cells that coexpress CCSP (ccg). (B) Representative photomicrographs of human large airway epithelial cells (hLAECs) cultured from COPD patients, incubated with IL-13 $(100 \mathrm{ng} / \mathrm{ml})$ for 5 days, and then immunostained for $\beta$-tubulin (red) and MUC5AC (green). (C) Representative photomicrographs of hLAECs cultured from control (non-COPD) subjects, incubated with IL-13 for 1 day, immunostained as in $\mathbf{B}$, and then viewed with laser confocal scanning microscopy in $x-y$ axis and $z$ axis views. In $\mathbf{B}$ and $\mathbf{C}$, arrows indicate cells that immunostained for both $\gamma$-tubulin and MUC5AC. Scale bar: $20 \mu \mathrm{m}$. also primarily responsible for airway repair in concert with EGFR expression but depends on a marked proliferative response $(14,54)$. The present findings therefore raised the unexpected possibility that prolonged EGFR-dependent cell survival (not proliferation) is critical for remodeling of epithelial structure toward a chronic asthma/bronchitis phenotype. Support for this possibility was obtained when we showed that EGFR blockade prevented ciliated cell hyperplasia in vivo and caused ciliated epithelial cell apoptosis in vitro. Additional study of airway epithelial cells cultured under physiologic conditions indicated that ciliated epithelial cell survival depends on uninterrupted EGFR signaling to PI3K. Otherwise, the ciliated cells proceed toward programmed cell death (via caspase activation) in a manner that appears analogous to virus-inducible apoptosis (38). The fidelity of the present model to human disease is supported by initial experiments that detect ciliated epithelial cells with activated EGFR in airway sections from subjects with asthma, but further studies will be needed to verify this finding and extend it to other chronic airway diseases. Nonetheless, the present findings indicate that the plasticity and responsiveness of ciliated cells in the setting of airway damage and inflammation is an underappreciated but seminal feature of airway epithelial remodeling.

The second major set of findings of the present study was focused on IL-13 signaling and the capacity of ciliated cells to transdifferentiate to goblet cells under IL-13 stimulation. This finding was also unexpected, since previous work had suggested that IL-13 may cause a decrease in ciliated cells and an increase in goblet cells, but no apparent connection was drawn between the 2 phenomena $(3,5)$. In the present work, we were able to capture snapshots of epithelial cells in vitro and in vivo that appear to be transitioning from a ciliated to a goblet cell phenotype under pressure from IL-13. In addition, we detected reciprocal increases in ciliated cell levels during IL-13 blockade in vivo. Additional cell lineage studies of this process are needed to fully define the mechanism of transdifferentiation, but the evidence points to a program that carefully coordi- nates ciliated and goblet cell formation to achieve proper mucosal immunity. Indeed, epithelial EGFR activation, ciliated cell hyperplasia, IL-13 production, and goblet cell metaplasia appear to develop together in time. This type of coordination is likely required for efficient mucociliary function. The present results suggest that abnormally prolonged IL-13 production may lead to goblet cell metaplasia beyond the initial repair phase and so explain how goblet cell metaplasia may develop in this setting. Thus, genetic susceptibility to the development of persistent EGFR activation as well as IL-13 production after viral infection may allow for the consequent development of goblet cell metaplasia. Whether a similar paradigm applies to other asthmagenic stimuli (e.g., allergen exposure) will need further study in models that mimic the human condition. Nonetheless, the fidelity of the present model to human disease is again supported by initial experiments that detect ciliated-to-goblet cell transdifferentiation in airway sections and cultured cells from patients with COPD likely under the influence of IL-13.

Together, our results on EGFR- and IL-13-dependent signaling provide a new paradigm for epithelial host defense and remodeling (summarized in Figure 10) that should be useful for developing a rational basis for therapies aimed at downregulating hypersecretory conditions. Thus, tyrosine kinase inhibitors in general and EGFR tyrosine kinase inhibitors in particular are being broadly developed for use in conditions exhibiting abnormal epithelial architecture, including asthma and COPD, but the cellular signaling context for their application to airway disease was uncertain. The present strategy utilized an irreversible inhibitor of EGFR tyrosine kinase activity that showed efficacy in preventing epithelial hyperplasia in a model of intestinal neoplasia (55). In that setting, the pharmacologic strategy was aimed at inhibiting epithelial proliferation, but our findings indicate that interrupting antiapoptotic signals may be the primary target in inflammatory airway disease. Further development of approaches for targeting EGFR (as well as those directed at IL-13-dependent events) will also benefit from further defining 


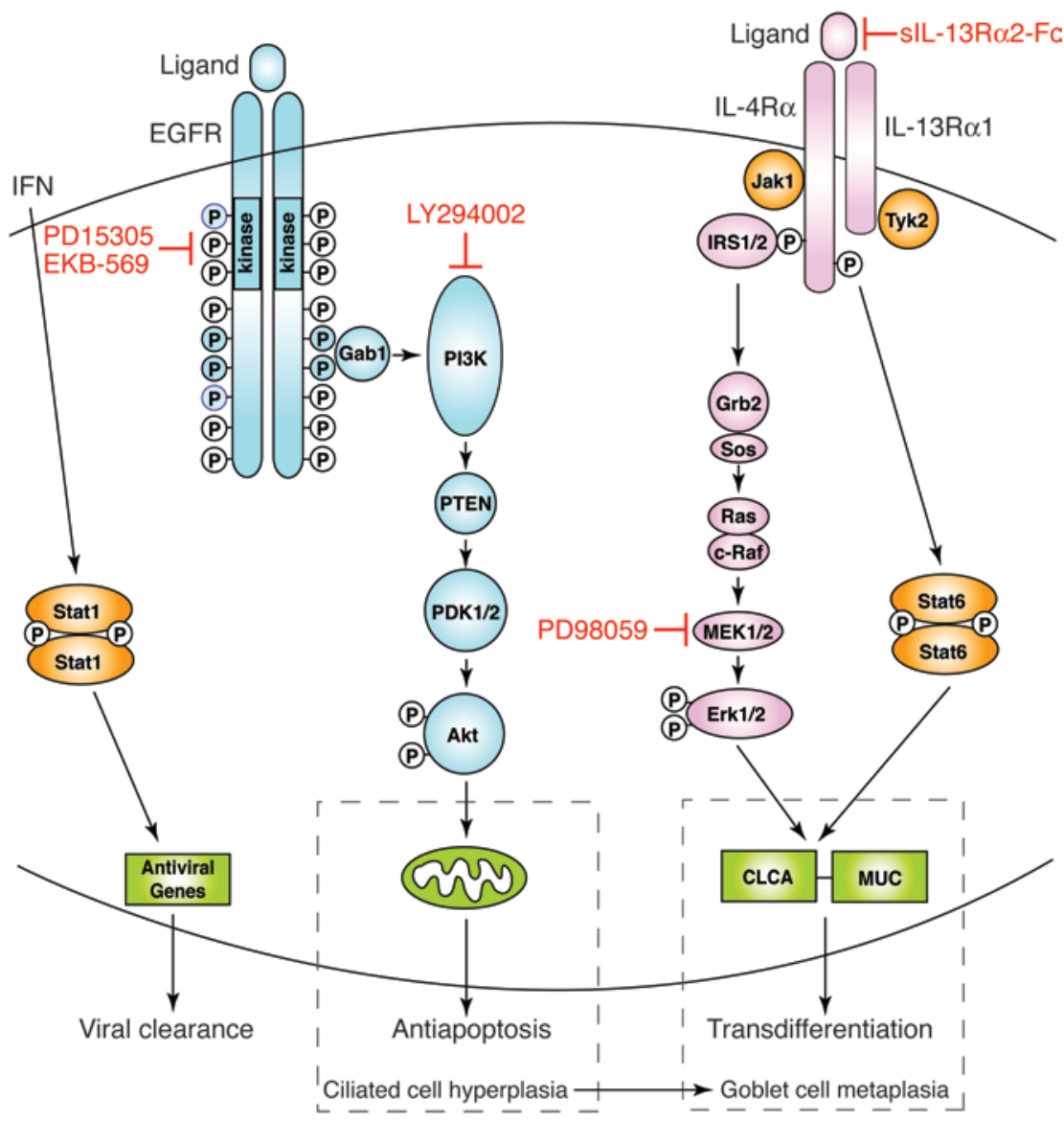

\section{Figure 10}

Scheme for virus-inducible EGFR- and IL-13dependent pathways controlling epithelial host response and remodeling. EGFR activation with receptor dimerization and receptor tyrosine kinase phosphorylation leads to Gab1 recruitment followed by PI3K activation that causes generation of phosphatidylinositol-3,4,5-phosphate $\left(\mathrm{PI}-3,4,5-\mathrm{P}_{3}\right)$ and activation of $\mathrm{PDK} 1 / 2$ and then Akt that inactivates proapoptotic factors at the level of the mitochondria and promote cell survival. IL-13 signaling activates IRS1/2-dependent cascade to ERK1/2 and Stat6, which each contribute to upregulation of genes (CLCA and $\mathrm{MUC}$ ) that promote cilia to goblet cell transdifferentiation. Under physiologic conditions, these pathways may (in conjunction with IFN-dependent activation of Stat1) lead to protection from viral infection, but if there is persistent activation in a susceptible genetic background, the same pathways may lead to ciliated cell hyperplasia and goblet cell metaplasia. Rational use of specific inhibitors, e.g., EGFR and IL-13R blockers, may fully restore normal epithelial architecture. Grb2, growth factor receptor-bound 2; PTEN, phosphatase and tensin homologue deleted on chromosome 10; Sos, son-of-sevenless. the signaling events that regulate airway epithelial cell apoptosis and transdifferentiation. In that regard, we provide evidence that downstream signaling to prevent epithelial cell apoptosis proceeds through EGFR-dependent PI3K but not MEK/ERK activation based on selective inhibition. This finding implies that the targeted pathway extends from EGFR homo- or heterodimerization and activation of the receptor tyrosine kinase cytosolic domain to autophosphorylation of tyrosine resides within the cytoplasmic domain, docking of Gab2/PI3K, and subsequent activation of Akt signaling (56).

As noted above, the present results for EGFR-PI3K survival signaling stand in some contrast to reports of EGFR and other signals to ERK1/2 to promote cell survival under other circumstances (51). In particular, respiratory syncytial virus may trigger EGFR and ERK1/2 activation (and IL-8 release) in cultured epithelial cells during the acute infection, but these studies were performed using transformed (A549) cells with necessarily altered death pathways or in submerged cell cultures that do not differentiate into ciliated epithelial cells (50). Nonetheless, acute infection with respiratory syncytial virus (as well as $\mathrm{SeV}$ and influenza virus) may promote epithelial cell survival in the acute setting based on chemokine-dependent activation of either PI3K/Akt or MEK/ERK signaling both in vitro (using well-differentiated mouse and human cells) and in vivo (using a mouse model of acute infection) (38). In contrast to the situation for acute infection, the present findings therefore highlight the change in epithelial survival signals in the chronic setting and are again remarkable for using high-fidelity models in vitro and in vivo to establish that EGFR signals via PI3K/Akt selectively regulate ciliated cell survival.
The selective effect of PI3K but not MEK1/2 inhibition in the present system may also indicate that there is little contribution from the interaction of downstream signaling pathway through positive- or negative-feedback mechanisms. There is, however, significant overlap between EGFR- and IL-13-signaling events despite distinct outcomes. EGFR activation of a PI3K/Akt signal is directed at preventing apoptosis, whereas IL-13 signaling to PI3K as well as ERK1/2 and Stat6 are all directed toward increasing CLCA and MUC gene expression to promote goblet cell formation (ref. 5 and A.C. Patel, J.D. Morton, and M.J. Holtzman, unpublished observations). The distinct outcomes of EGFR and IL-13 activation of PI3K and ERK1/2 are likely related to further diversity in downstream signaling. For example, EGFR survival signals may be mediated by Akt-dependent phosphorylation and inactivation of the proapoptotic factor BAD whereas other downstream targets of Akt may contribute to mucin gene expression $(57,58)$. The present results help to lay the biologic basis for defining these downstream events.

The present results complement previous results suggesting that Clara cells also give rise to mucous cells. Thus, allergen-induced goblet cell metaplasia is accompanied by morphologic and biochemical evidence of CCSP-positive Clara cells containing mucous granules in mice (22-24). Inhibitor effects were not reported in those studies, but at least 1 report showed a decrease in Clara cell level concomitant with an increase in goblet cell level consistent with Clara-to-goblet cell transdifferentiation (22). Similarly, others used the rat CCSP promoter to delete endogenous IL-13R signaling and downregulate mucous cell metaplasia in allergen-challenged mice (6). Given the present results, residual metaplasia in that model may have been 
derived from ciliated cells. However, comparison to the present results is complicated by the change in stimulus (from allergen to virus) and genetic background (from Balb/cJ to C57BL/6J). Moreover, IL-13 may regulate CCSP expression (Y. You and S. Brody, unpublished observations, and ref. 25), and the rat CCSP promoter system may not be specific for mouse Clara cell expression. In fact, significant levels of CCSP-driven recombination can be found in ciliated airway epithelial cells (59). Thus, it may be necessary to track other markers of Clara cell lineage to fully define the relative contribution of Clara versus ciliated cell populations to goblet cell metaplasia. We found virus-induced decreases in Clara cell levels that were reversed by EGFR blockade but unchanged after IL-13 inhibition, so the significance of any Clara cell contribution to mucous cell metaplasia after viral infection remains uncertain. Nonetheless, the present observations of CCSP and $\beta$-tubulin colocalization with MUC5AC in mice and in humans suggests that ciliated and Clara cells may each demonstrate sufficient plasticity to contribute to mucous cell metaplasia.

Taken together, the present report extends the line of reasoning that airway epithelial cells may be specially programmed for normal immune defense (especially against respiratory viruses) and abnormally programmed in airway disease. Previous work focused on other epithelial immune responses (notably interferon signaling) and how the epithelium clears infection in the short term $(60,61)$, whereas the present work focuses on EGFR and IL-13 and how the epithelium responds in the long term. Similar to other epithelial responses, the EGFR and IL-13 signals were likely developed to protect host epithelial cells from the lethal effect of viruses and to optimize mucosal immunity. As noted above (Figure 10), the epithelial EGFR antiapoptotic system may protect the host cell (often the ciliated cell) from cytopathic effects that allow spread of infection. In parallel, the IL-13 goblet cell system may direct increases in mucus formation to aid mucociliary clearance of cellular and microbial debris from the airway. Both of these strategies are likely achieved in concert with epithelial interferon signaling that also protects the host cell by inhibiting viral replication. The present work adds the critical piece that demonstrates how, in some genetic settings, this normally protective response may be skewed toward a persistent response that results in a chronic asthma/bronchitis phenotype. Further study is needed to determine whether this genetic susceptibility is linked to EGFR mutations that confer antiapoptotic signals and inhibitor sensitivity in lung cancer cells (62) or whether persistent EGFR activation is connected to IFN signaling and chronic Stat 1 activation found in asthma (63), as may be the case in other epithelial barriers (64). Nonetheless, the present results demonstrate that the abnormality in epithelial immune-response programming can be corrected by targeted inhibition of critical signaling steps. Treatment with EGFR tyrosine kinase inhibitors allows for the ciliated cells to proceed toward programmed cell death in a manner that appears analogous to virus-inducible apoptosis while IL-13 blockade appears to prevent the transition from ciliated to goblet cells. This new scheme thereby indicates that epithelial remodeling toward an asthma/bronchitis phenotype depends on both EGFR survival and IL-13 transdifferentiation signals such that treatment to block both of these signals would be required to fully restore the airway epithelium to its original architecture.

\section{Methods}

Mice and viral inoculation. C57BL/6J and Balb/cJ mice were obtained from Jackson Laboratory at 5 weeks of age and were maintained for study at 6-7 weeks of age as described previously (36-38) under protocols approved by the Washington University Animal Studies Committee. $\mathrm{SeV}$ was grown in embryonated hen eggs and harvested to provide a viral stock solution such that $5000 \mathrm{EID}_{50}\left(50 \%\right.$ egg infectious dose) was equivalent to $2 \times 10^{5} \mathrm{PFUs}$. This inoculum or an equivalent amount of UV-inactivated $\mathrm{SeV}$ was delivered intranasally in $30 \mu \mathrm{l}$ PBS under ketamine/xylazine anesthesia. Under these conditions, viral tissue levels are maximal at 3-5 days after inoculation, and viral clearance is complete by day 12 (36-38). Sentinel mice and experimental control mice were handled identically to inoculated mice and exhibited no serologic or histologic evidence of exposure to 11 rodent pathogens (including SeV). For EGFR blockade, mice were treated with EKB-569 (obtained from L.M. Greenberger, Wyeth Pharmaceuticals, Pearl River, New York, USA; 20 mg/kg in pH 2.0 water given by gavage) or vehicle control given daily for postinfection days $10-21$. For IL-13 blockade, mice were given subcutaneous injections of sIL-13R $\alpha 2-\mathrm{Fc}$ (obtained from D.D. Donaldson, Wyeth Ayerst, Cambridge, Massachusetts, USA; 200 g/mouse in PBS) or control Fc at 12, 14, 17, and 20 days after inoculation.

Histochemistry. Mouse lung was fixed by intratracheal instillation of $4 \%$ paraformaldehyde at $25-\mathrm{cm} \mathrm{H}_{2} \mathrm{O}$ pressure, embedded in paraffin, and cut into $3-\mu \mathrm{m}$ thick sections for $\mathrm{H} \& \mathrm{E}$ or immunostaining. For immunostaining, tissue sections were deparaffinized, rehydrated in graded alcohol, and encircled with a hydrophobic film (ImmEdge PEN; Vector Laboratories). For antigen retriev$\mathrm{al}$, sections were digested with proteinase $\mathrm{K}$ (Sigma-Aldrich) at a final concentration of $40 \mu \mathrm{g} / \mathrm{ml}$ in PBS for 5 minutes and then treated in 3\% hydrogen peroxide in distilled water for 10 minutes to quench endogenous peroxidase activity. Nonspecific protein binding was blocked with $3 \%$ BSA and $2 \%$ goat serum in Tris-buffered saline ( $\mathrm{pH}$ 8.0) with $0.2 \%$ Tween 20 (TBST) for 1 hour. Primary antibodies were diluted in blocking buffer and incubated overnight at $4^{\circ} \mathrm{C}$ at a final concentration of 0.05 or $0.1 \mu \mathrm{g} / \mathrm{ml}$ for human and mouse tissue sections, respectively. EGFR was detected using rabbit anti-human EGFR antibody SC-03 (Santa Cruz Biotechnology Inc.) directed against amino acid residues 1005-1016, which are identical to corresponding sequences in murine EGFR. Phosphorylated EGFR ( $\mathrm{p}$-EGFR) was detected using rabbit anti-p-EGFR $\left(\mathrm{Tyr}^{845}\right.$ ) antibody 2231 (Cell Signaling Technology) directed against phosphorylated $\mathrm{Tyr}^{845}$. For this antibody, final concentrations of 0.16 and $0.32 \mu \mathrm{g} / \mathrm{ml}$ were used for human and mouse tissues, respectively. Ciliated, Clara, and goblet cells were identified using mouse anti- $\beta$-tubulin IV mAb (Sigma-Aldrich), goat anti-CCSP antibody (Santa Cruz Biotechnology), and mouse anti-human MUC5AC mAb 45M1 (Lab Vision Corp.), respectively. To verify specificity, sections were also incubated with primary antibodies that were preabsorbed with 10-fold excess of peptide antigen or with nonimmune rabbit IgG (Santa Cruz). After primary antibody binding, sections were washed with TBST and then incubated with biotinylated goat anti-rabbit IgG $(2 \mu \mathrm{g} / \mathrm{ml})$. Signals were amplified with the Elite ABC method and 3,3'-diaminobenzidine chromogen according to the manufacturer's protocols (Vector Laboratories). Sections were counterstained with hematoxylin, dehydrated, and mounted with Cytoseal 60 (Stephens Scientific).

Immunofluorescence was performed in the same manner as immunostaining for light microscopy except that tissues were frozen in Tissue-Tek OCT (Sakura Finetek Co.), sections were blocked with $2 \%$ donkey serum (Jackson ImmunoResearch Laboratories Inc.), primary antibody binding was detected using CY-3- or FITC-conjugated antibodies (Jackson ImmunoResearch Laboratories Inc.) for 30 minutes at $25^{\circ} \mathrm{C}$, and sections were counterstained with Hoechst dye 33432 (Invitrogen Corp.). Sections were imaged with light or immunofluorescent microscopy (BX-51; Olympus) interfaced to a digital photomicrography system (CCD Camera and MagnaFire software, version 2; Optronix). Reporter was quantified by counting ciliated cells in pulmonary airways per mm of basement membrane with analysis performed using the NIH Image program (http://rsb.info.nih.gov/nih-image), as described previously $(36,37,63)$. Confocal microscopy was performed using a Zeiss laser scanning system with LSM-S10 software, version 3.2. 
Human tissue procurement and analysis. Asthmatic patients with and without glucocorticoid treatment and healthy control subjects were recruited, characterized, and subjected to endobronchial biopsy as described previously $(37,63)$. Endobronchial biopsies were washed with PBS and incubated with $10 \%$ neutral buffered formalin for 18 hours at $25^{\circ} \mathrm{C}$ followed by histochemistry as described above. In addition, we obtained lung tissue samples from COPD patients who were undergoing lung resection or transplantation and processed them as described above. All human studies were approved by the Washington University Human Studies Committee, and all subjects gave informed consent.

Proliferation markers. For BrdU immunostaining, mice received BrdU $(100 \mathrm{mg} / \mathrm{kg})$ intraperitoneally at 48 hours, 24 hours, and 4 hours prior to euthanasia. BrdU was detected with an anti-BrdU staining kit (Zymed Laboratories Inc.) according to the manufacturer's protocol. Ki67 immunostaining, was performed with anti-Ki67 Ab (Novocastra) using the same protocol as for EGFR immunostaining except for pretreatment of heat-induced antigen retrieval using Antigen Unmasking Solution (Vector Laboratories). PCNA staining was performed with biotinylated anti-mouse PCNA Ab (DakoCytomation) using the ABC method (Vector Laboratories).

Airway epithelial cell culture and treatment. Primary air-liquid interface cultures of mTECs were established as described previously (53). Human airway epithelial cell cultures were established from tracheobronchial specimens harvested from lung explants of COPD patients undergoing transplantation and from lung transplant donors without lung disease using the same culture conditions. In all cases, cells were grown in basic medium (DMEM/Ham's F-12 with 30 mM HEPES, 4 mM L-glutamine, 3.5 mM NaHCO 3 , 0.01\% Fungizone, and penicillin/streptomycin) supplemented with $10 \mu \mathrm{g} / \mathrm{ml}$ insulin, $10 \mu \mathrm{g} / \mathrm{ml}$ transferrin, $0.1 \mu \mathrm{g} / \mathrm{ml}$ cholera toxin, $25 \mathrm{ng} / \mathrm{ml}$ EGF (BD), $30 \mu \mathrm{g} / \mathrm{ml}$ bovine pituitary extract, and 5\% FBS in the upper and lower compartments. After the cells developed transmembrane electrical resistance greater than $1000 \mathrm{Ohm} / \mathrm{cm}^{2}$, the air-liquid interface condition was established by washing the membrane with PBS and changing the medium in the lower compartment to basic medium supplemented with $2 \%$ NuSerum (BD Biosciences). For EGFR stimulation, cells were incubated in basic medium for 24 hours and then in basic medium containing EGF (1-100 ng/ml; Upstate Biotechnology) added to the upper and/or lower compartments for 10 minutes at $37^{\circ} \mathrm{C}$. EGFR signaling inhibitors or vehicle control ( $0.1 \% \mathrm{DMSO})$ were added to the lower compartments on a daily basis for long-term experiments or for 1.5-6 hours to the upper and lower compartments for short-term experiments. EGFR tyrosine kinase inhibitor PD153035, MEK1/2 inhibitor PD98059, EGFR tyrosine kinase inhibitor AG1478, and PI3K inhibitor LY294002 were from Calbiochem, and z-VAD-fmk was from Enzyme Systems Products. Recombinant human or mouse IL-13 from Preprotech was added to upper and lower compartments at 24 hours before air-liquid interface conditions and was maintained in the lower compartment throughout the experiment.

Western blotting. For whole lung analysis, the left lobe of mouse lung was homogenized in RIPA buffer (1\% NP-40, $0.5 \%$ sodium deoxycholate, $0.1 \%$ SDS in PBS) containing phosphatase inhibitor cocktail (Sigma-Aldrich). Tracheal tissue and mTECs were collected in cell lysis buffer containing $20 \mathrm{mM}$ Tris-HCl, 150 mM NaCl, 1 mM EDTA, 1 mM EGTA, 1\% Triton-X 100, $1.0 \mu \mathrm{g} / \mathrm{ml}$ leupeptin, $10 \mu \mathrm{g} / \mathrm{ml}$ aprotinin, $0.2 \mathrm{mM}$ phenylmethylsulfonyl fluoride, $1 \mathrm{mM}$ sodium orthovanadate, $0.1 \mathrm{mM}$ sodium fluoride, $2.5 \mathrm{mM}$ sodium pyrophosphate, and $1 \mathrm{mM} \beta$-glycerophosphate. Cell lysates were cleared by centrifugation, and supernatant proteins were separated on 4-15\% gradient SDS-PAGE and transferred to PVDF membranes (Millipore). The membranes were blotted against antibodies to EGFR, p-EGFR, p-ERK1/2, activated caspase-3, p-Stat6 (Cell Signaling Technology), p-Akt (BD Biosciences), caspase-9 (Stressgen Biotechnologies), and $\beta$-actin (Chemicon International). Primary antibody binding was detected with secondary antibodies conjugated to horseradish peroxidase and enhanced chemiluminescence (Amersham Pharmacia Biotech).

Immunocytochemistry. Cultured cells were washed twice with PBS at $4^{\circ} \mathrm{C}$, fixed in $4 \%$ paraformaldehyde for 10 minutes at $25^{\circ} \mathrm{C}$, washed with PBS, and permeabilized with ethanol:acetic acid $(2: 1, \mathrm{vol} / \mathrm{vol})$ for 5 minutes at $-20^{\circ} \mathrm{C}$ for TUNEL reaction or with $0.2 \%$ Triton- $\mathrm{X}$ for 5 minutes at $25^{\circ} \mathrm{C}$ for immunostaining. Permeabilized cells were then washed with PBS and subjected to the TUNEL reaction (Intergen Co.) or blocked with 2\% fish gel for 1 hour at $25^{\circ} \mathrm{C}$ and incubated with rabbit anti-active caspase-3 (BD Biosciences), rabbit anti-EGFR (Santa Cruz Biotechnology Inc., rabbit anti-p-EGFR (Cell Signaling Technology), mouse anti- $\beta$-tubulin IV, or rabbit anti- $\gamma$-tubulin (Sigma-Aldrich) antibodies overnight at $4{ }^{\circ} \mathrm{C}$. Primary antibody binding was detected with goat anti-mouse or donkey anti-rabbit FITC or CY3 secondary antibody. Cells were counterstained with $4 \mu \mathrm{g} / \mathrm{ml}$ Hoescht 33258 (Invitrogen Corp.) to check nuclear morphology, and then imaged as described above.

Flow cytometry. mTECs were cultured as above and removed from Transwell culture using cell dissociation solution (Sigma-Aldrich) containing $0.25 \%$ trypsin and $0.1 \%$ EDTA. Cells were washed with HBSS containing $0.2 \% \mathrm{BSA}$ and incubated with $5 \mu \mathrm{g} / \mathrm{ml} \mathrm{JC}-1$ (Invitrogen Corp.) for $15 \mathrm{~min}$ utes at $25^{\circ} \mathrm{C}$. Cells with mitochondrial membrane depolarization were detected by a shift from low to high emission in green fluorescence (FL1) using a FACSCalibur flow cytometer and CellQuest software (BD).

Electron microscopy. Cells on membranes were prepared for transmission electron microscopy (TEM) as previously described (53). In brief, samples were fixed with $2.5 \%$ glutaraldehyde and stained with $1.25 \%$ osmium tetroxide. Cells were counterstained with $2.0 \%$ tannic acid, blocked for sectioning, and imaged on a Zeiss 902 model microscope.

Statistics. Values for histochemistry of mouse tissues were analyzed using a 1-way analysis of variance (ANOVA) for a factorial experimental design. If significance was achieved by 1 -way analysis, post-ANOVA comparison of means was performed using Scheffe's F test. $P<0.05$ was considered statistically significant.

\section{Acknowledgments}

This research was supported by grants from the National Heart, Lung, and Blood Institute and the Alan A. and Edith L. Wolff Charitable Trust.

Received for publication March 28, 2005, and accepted in revised form October 25, 2005.

Address correspondence to: Michael J. Holtzman, Washington University School of Medicine, Campus Box 8052, 660 South Euclid Avenue, St. Louis, Missouri 63110, USA. Phone: (314) 3628970; Fax: (314) 362-8987; E-mail: holtzman@im.wustl.edu.
1. Grunig, G., et al. 1998. Requirement for IL-13 independently of IL-4 in experimental asthma. Science. 282:2261-2263.

2. Wills-Karp, M., et al. 1998. Interleukin-13: central mediator of allergic asthma. Science. 282:2258-2261.

3. Laoukili, J., et al. 2001. IL-13 alters mucociliary differentiation and ciliary beating of human respiratory epithelial cells. J. Clin. Invest. 108:1817-1824. doi:10.1172/JCI200113557.
4. Kondo, M., Tamaoki, J., Takeyama, K., Nakata, J., and Nagai, J. 2002. Interleukin-13 induces goblet cell differentiation in primary cell culture from guinea pig tracheal epithelium. Am. J. Respir. Cell Mol. Biol. 27:536-541.

5. Atherton, H.C., Jones, G., and Danahay, H. 2003. IL-13-induced changes in the goblet cell density of human bronchial epithelial cell cultures: MAP kinase and phosphatidylinositol 3-kinase regulation. Am.J.
Physiol. Lung Cell. Mol. Physiol. 285:L730-L739.

6. Kuperman, D.A., et al. 2005. IL-4 receptor signaling in Clara cells is required for allergen-induced mucus production. J. Immunol. 175:3746-3752.

7. Schmid-Grendelmeier, P., et al. 2002. Eosinophils express functional IL-13 in eosinophilic inflammatory diseases. J. Immunol. 169:1021-1027.

8. Miotto, D., et al. 2003. Interleukin-13 and -4 expression in the central airways of smokers with 
chronic bronchitis. Eur. Respir. J. 22:602-608.

9. Berry, M.A., et al. 2004. Sputum and bronchial submucosal IL-13 expression in asthma and eosiniophililc bronchitis. J. Allergy Clin. Immunol. 114:1106-1109.

10. Danahay, H., Atherton, H.C., Jones, G., Bridges, R.J., and Poll, C.T. 2002. Interleukin-13 induces a hyper-secretory ion transport phenotype in human bronchial epithelial cells. Am. J. Physiol. Lung Cell. Mol. Physiol. 282:L226-L236.

11. Hoshino, M., et al. 2002. Increased expression of the human $\mathrm{Ca}^{+}$-activated $\mathrm{Cl}^{-}$channel 1 (CaCC1) gene in the asthmatic airway. Am. J. Respir. Crit. Care Med. 165:1132-1136.

12. Aida, S., Tamai, S., Sekiguchi, S., and Shimizu, N. 1994. Distribution of epidermal growth factor and epidermal growth factor receptor in human lung: immunohistochemical and immunoelectronmicroscopic studies. Respiration. 61:161-166.

13. Strandiford, T.P., Clark, J.G., Guralnick, D.E., and Madtes, D.K. 1995. Immunolocalization of transforming growth factor- $\alpha$, epidermal growth factor (EGF), and EGF-receptor in normal and injured developing human lung. Pediatr. Res. 38:851-856.

14. Van Winckle, L.S., Isaac, J.M., and Plopper, C.G. 1997. Distribution of epidermal growth factor receptor and ligands during bronchiolar epithelial repair from naphthalene-induced Clara cell injury in the mouse. Am. J. Pathol. 151:443-459.

15. Amishima, M., et al. 1998. Expression of epidermal growth factor and epidermal growth factor receptor immunoreactivity in the asthmatic human airway. Am. J. Respir. Crit. Care Med. 157:1907-1912.

16. Hardie, W.D., et al. 1998. Immunolocalization of transforming growth factor $\alpha$ and epidermal growth factor receptor in lungs of patients with cystic fibrosis. Pediatr. Dev. Pathol. 2:415-423.

17. Takeyama, K., et al. 1999. Epidermal growth factor system regulates mucin production in airways. Proc. Natl. Acad. Sci. U. S. A. 96:3081-3086.

18. Polosa, R., et al. 1999. Expression of c-erbB receptors and ligands in human bronchial mucosa. Am. J. Respir. Cell Mol. Biol. 20:914-923.

19. Puddicombe, S.M., et al. 2000. The involvement of the epidermal growth factor receptor in epithelial repair in asthma. FASEBJ. 14:1362-1374.

20. Takeyama, K., Fahy, J.V., and Nadel, J.A. 2001. Relationship of epidermal growth factor receptors to goblet cell production in human bronchi. Am. J. Respir. Crit. Care Med. 163:511-516.

21. Shim, J.J., et al. 2001. IL-13 induces mucin production by stimulating epidermal growth factor receptors and by activating neutrophils. Am. J. Physiol. 280:L134-L140.

22. Reader, J.R., et al. 2003. Pathogenesis of mucous cell metaplasia in a murine asthma model. Am. J. Pathol. 162:2069-2078.

23. Hayashi, T., Ishii, A., Nakai, S., and Hasegawa, K. 2004. Ultrastructure of goblet-cell metaplasia from Clara cell in the allergic asthmatic airway inflammation in a mouse model of asthma in vivo. Virchows Arch. 444:66-73.

24. Evans, C.M., et al. 2004. Mucin is produced by Clara cells in the proximal airway of antigen-challenged mice. Am. J. Respir. Cell Mol. Biol. 31:382-394.

25. Kim, S., et al. 2002. IL-13-induced Clara cell secretory protein expression in airway epithelium: role of EGFR signaling pathway. Am. J. Physiol. Lung Cell. Mol. Physiol. 283:L67-L75.

26. Wu, W., et al. 1999. Activation of the EGF receptor signaling pathway in human airway epithelial cells exposed to metals. Am. J. Physiol. 277:L924-L931.

27. Takeyama, K., et al. 2000. Oxidative stress causes mucin synthesis via transactivation of epidermal growth factor: role of neutrophils. J. Immunol. 164:1546-1552.

28. Burgel, P.-R., et al. 2001. Human eosinophils induce mucin production in airway epithelial cells via epidermal growth factor receptor activation. J. Immunol. 167:5948-5954.

29. Lemjabbar, H., and Basbaum, C. 2002. Plateletactivating factor receptor and ADAM10 mediate responses to Staphylococcus aureus in epithelial cells. Nat. Med. 8:41-46.

30. Hamilton, L.M., et al. 2003. The role of epidermal growth factor receptor in sustaining neutrophil inflammation in severe asthma. Clin. Exp. Allergy. 33:233-240.

31. Shao, M.X.G., Ueki, I.F., and Nadel, J.A. 2003. Tumor necrosis factor $\alpha$-converting enzyme mediates MUC5AC mucin gene expression in cultured human airway epithelial cells. Proc. Natl. Acad. Sci. U. S. A. 100:11618-11623.

32. Moghal, N., and Neel, B.G. 1998. Integration of growth factor, extracellular matrix, and retinoid signals during bronchial epithelial cell differentiation. Mol. Cell. Biol. 18:6666-6678.

33. Wu, W., Samet, J.A., Ghio, A.J., and Devlin, R.B. 2001. Activation of the EGF receptor signaling pathway in airway epithelial cells exposed to Utah Valley PM. Am. J. Physiol. 28:L483-L489.

34. Zhang, L., et al. 2001. Vanadium stimulates human bronchial epithelial cells to produce heparin-binding epidermal growth factor-like growth factor. Am. J. Respir. Cell Mol. Biol. 24:123-131.

35. Gray, T.E., Guzman, K., Davis, C.W., Abdullah, L.H., and Nettesheim, P. 1996. Mucociliary differentiation of serially passaged normal human tracheobronchial epithelial cells. Am. J. Respir. Cell Mol. Biol. 14:104-112.

36. Walter, M.J., Morton, J.D., Kajiwara, N., Agapov, E., and Holtzman, M.J. 2002. Viral induction of a chronic asthma phenotype and genetic segregation from the acute response. J. Clin. Invest. 110:165-175. doi:10.1172/JCI200214345.

37. Walter, M.J., Kajiwara, N., Karanja, P., Castro, M., and Holtzman, M.J. 2001. IL-12 40 production by barrier epithelial cells during airway inflammation. J. Exp. Med. 193:339-352.

38. Tyner, J.W., et al. 2005. CCL5/CCR5 interaction provides antiapoptotic signals for macrophage survival during viral infection. Nat. Med. 11:1180-1187.

39. Lin, S.-Y., et al. 2001. Nuclear localization of EGF receptor and its potential new role as a transcription factor. Nat. Cell Biol. 3:802-808.

40. Johnson, M.D., Gray, M.E., Carpenter, G., Pepinsky, R.B., and Stahlman, M.T. 1990. Ontogeny of epidermal growth factor receptor and lipocortin-1 in fetal and neonatal human lungs. Hum. Pathol. 21:182-191.

41. Ruocco, S., Lallemand, A., Tournier, J.M., and Gaillard, D. 1996. Expression and localization of epidermal growth factor, transforming growth factor-alpha, and localization of their common receptor in fetal human lung development. Pediatr. Res. 39:448-455.

42. Lei, Z.M., and Rao, C.V. 1992. Expression of epidermal growth factor (EGF) receptor and its ligands, EGF and transforming growth factor-alpha, in human fallopian tubes. Endocrinology. 131:947-957.

43. Schell, D.L., Mavrogianis, P.A., Fazleabas, A.T., and Verhage, H.G. 1994. Epidermal growth factor, transforming growth factor-alpha, and epidermal growth factor receptor localization in the baboon (Papio anubis) oviduct during steriod treatment and the menstrual cycle. J. Soc. Gynecol. Investig. 1:269-276.

44. Gesualdo, L., et al. 1996. Expression of epidermal growth factor receptor and its receptor in normal and diseased human kidney: an immunohistochemical and in situ hybridization study. Kidney Int. 49:656-665.

45. Playford, R.J., et al. 1996. The epidermal growth factor receptor (EGF-R) is present on the basolateral, but not the apical, surface of enterocytes in the human gastrointestinal tract. Gut. 39:262-266.

46. Vermeer, P.D., et al. 2003. Segregation of receptor and ligand regulates activation of epithelial growth factor receptor. Nature. 422:322-326.

47. Look, D.C., et al. 2001. Effects of paramyxoviral infection on airway epithelial cell Foxj1 expression, ciliogenesis, and mucociliary function. Am.J. Pathol. 159:2055-2069.

48. Pack, R.J., Layla, H., Ugaily, A., Morris, G., and Widdicombe, J.G. 1980. The distribution and structure of cells in the tracheal epithelium of the mouse. Cell Tissue Res. 208:65-84.

49. Kuwada, S.K., et al. 1998. Differential signaling and regulation of apical vs. basolateral EGFR in polarized epithelial cells. Am. J. Physiol. Cell Physiol. 275:C1419-C1428.

50. Monick, M.M., et al. 2005. Activation of epidermal growth factor receptor by respiratory syncytial virus results in increased inflammation and delayed apoptosis. J. Biol. Chem. 280:2147-2158.

51. Roux, P.P., and Blenis, J. 2004. ERK and p38 MAPKactivated protein kinases: a family of protein kinases with diverse biological functions. Microbiol. Mol. Biol. Rev. 68:320-344.

52. Boers, J.E., Ambergen, A.W., and Thunnissen, F.B.J.M. 1999. Number and proliferation of Clara cells in normal human airway epithelium. Am.J. Respir. Crit. Care Med. 159:1585-1591.

53. You, Y., et al. 2004. The role of f-box factor foxj1 in differentiation of ciliated airway epithelial cells. Am. J. Physiol. Lung Cell. Mol. Physiol. 286:L650-L657.

54. Lawson, G.W., et al. 2002. Mouse strain modulates the role of the ciliated cell in acute tracheobronchial airway injury-distal airways. Am. J. Pathol. 160:315-327.

55. Torrance, C.J., et al. 2000. Combinatorial chemoprevention of intestinal neoplasia. Nat. Med. 6:1024-1028

56. Hackel, R.O., Zwick, E., Prenzel, N., and Ullrich, A. 1999. Epidermal growth factor receptors: critical mediators of multiple receptor pathways. Curr. Opin. Cell Biol. 11:177-183.

57. Wang, Y., McCullough, K.D., Franke, T.F., and Holbrook, N.J. 2000. Epidermal growth factor receptordependent Akt activation by oxidative stress enhances cell survival. J. Biol. Chem. 275:14624-14631.

58. Gilmore, A.P., et al. 2002. Activation of BAD by therapeutic inhibition of epidermal growth factor receptor and transactivation by insulin-like growth factor receptor. J. Biol. Chem. 277:27643-27650.

59. Perl, A.-K.T., et al. 2005. Conditional recombination reveals distinct subsets of epithelial cells in trachea, bronchi, alveoli. Am. J. Respir. Cell Mol. Biol. 33:455-462.

60. Zhang, Y., et al. 2005. Modification of the Stat 1 SH2 domain broadly improves interferon efficacy in proportion to $\mathrm{p} 300 / \mathrm{CBP}$ coactivator recruitment. J. Biol. Chem. 280:34306-34315.

61. Lo, M.S., Brazas, R.M., and Holtzman, M.J. 2005. Respiratory syncytial virus nonstructural proteins NS1 and NS2 mediate inhibition of Stat 2 expression and type I interferon responsiveness. J. Virol. 79:9315-9319.

62. Sordella, R., Bell, D.W., Haber, D.A., and Settleman, J. 2004. Gefitinib-sensitizing EGFR mutations in lung cancer activate anti-apoptotic pathways. Science. 305:1163-1167.

63. Sampath, D., Castro, M., Look, D.C., and Holtzman, M.J. 1999. Constitutive activation of an epithelial signal transducer and activator of transcription (Stat1) pathway in asthma. J. Clin. Invest. 103:1353-1361.

64. Andl, C.D., et al. 2004. EGFR induced cell migration is mediated predominantly by the JAK-STAT pathway in primary esophageal keratinocytes. Am.J. Physiol. Gastrointest. Liver Physiol. 287:G1227-G1237. 